\title{
Determination of Vertical Velocity Field of Southernmost Longitudinal Valley in Eastern Taiwan: A Joint Analysis of Leveling and GPS Measurements
}

\author{
Horng-Yue Chen ${ }^{1, *}$, Jian-Cheng Lee ${ }^{1}$, Hsin Tung ${ }^{1}$, Shui-Beih Yu ${ }^{1}$, Ya-Ju Hsu ${ }^{1}$, and Hungkyu Lee ${ }^{2}$ \\ ${ }^{1}$ Institute of Earth Sciences, Academia Sinica, Taipei, Taiwan \\ ${ }^{2}$ Department of Civil Engineering, Changwon National University, Gyeongnam, Korea
}

Received 29 June 2011, accepted 29 February 2012

\begin{abstract}
In order to provide a detailed vertical velocity field in southernmost Longitudinal Valley where shows a complex threefault system at the plate suture between Philippine Sea plate and Eurasia, we conducted leveling and GPS measurements, compiled data from previous surveys and combined them into a single data set. We compiled precise leveling results from 1984 to 2009, include 5 E-W trending and one N-S trending routes. We calculated the GPS vertical component from 10 continuous stations and from 89 campaign-mode stations from 1995 to 2010. The interseismic vertical rates are estimated by removing the co- and post-seismic effects of major large regional and nearby earthquakes. A stable continuous station S104 in the study area was adopted as the common reference station. We finally establish a map of the interseismic vertical velocity field. The interseismic vertical deformation was mainly accommodated by creeping/thrusting along two east-dipping strands of the three-fault system: the Luyeh and Lichi faults. The most dominant uplift of $30 \mathrm{~mm} \mathrm{yr}^{-1}$ occurs at the hanging wall of the Lichi fault on the western Coastal Range. However the rate diminishes away from the fault in the hanging wall. The Quaternary tablelands inside of the Longitudinal Valley reveals uplift with a rate of $5-10 \mathrm{~mm} \mathrm{yr}^{-1}$. Outside of the tablelands, the rest of the Longitudinal Valley flat area indicates substantial subsidence of -10 to $-20 \mathrm{~mm} \mathrm{yr}^{-1}$. Finally, it appears that the west-dipping blind fault under the eastern side of the Central Range does not play a significant role on interseismic deformation with subsidence rate of -5 to $-10 \mathrm{~mm} \mathrm{yr}^{-1}$.
\end{abstract}

Key words: Precise leveling, GPS, Interseismic vertical velocity, Longitudinal Valley, Taiwan

Citation: Chen, H. Y., J. C. Lee, H. Tung, S. B. Yu, Y. J. Hsu, and H. Lee, 2012: Determination of vertical velocity field of southernmost Longitudinal Valley in eastern Taiwan: A joint analysis of leveling and GPS measurements. Terr. Atmos. Ocean. Sci., 23, 355-376, doi: 10.3319/TAO 2012.02.29.01(TT)

\section{INTRODUCTION}

The island of Taiwan is located in a converging boundary between the Philippine Sea and Eurasian plates. The Longitudinal Valley in eastern Taiwan is considered to be an on-land suture between these two colliding plates (Biq 1972; Ho 1975; Angelier 1994). A variety of geodetic measurements have been conducted and analyzed along the Longitudinal Valley area over the past 30 years, primarily including leveling, trilateration surveys, Global Positioning System (GPS) measurements, and InSAR analyses (Lee and Yu 1985; Yu and Lee 1986; Liu and Yu 1990; Yu et al. 1992; Lee and Angelier 1993; Yu and Chen 1994; Yu and Kuo 2001; Hsu and Bürgmann 2006; Lee et al. 2006; Chen

\footnotetext{
* Corresponding author

E-mail: chenhy@earth.sinica.edu.tw
}

et al. 2009; Peyret et al. 2011; Yen et al. 2011). The results allowed better location of surface traces of the major active faults and to characterize the associated surface deformation. Across the middle and southern part of the Longitudinal Valley, a rapid rate of about $30 \mathrm{~mm} \mathrm{yr}^{-1}$ of interseismic horizontal movement was obtained and was attributed to the continuous creep along a single major reverse fault, the Longitudinal Valley fault (LVF).

On the other hand, the crustal deformation revealed a different pattern with regard to the northern and southernmost areas of the Longitudinal Valley fault. The northernmost segments of the Longitudinal Valley (i.e., the Lingting fault, the Yuemei fault and Milun fault) seem to be in locked state (Chen et al. 2009; Yen et al. 2011). In contrast, the faults showed rapid creep in the southernmost Longitudinal Valley (i.e., the study area of this paper), 
which is accommodated by two parallel strands of the LVF on both sides of the valley (Fig. 1), the Lichi fault and the Luyeh fault (Yu et al. 1990; Lee et al. 1998. Yu and Kuo 2001), together with a likely blind west-dipping fault under the western margin of the valley (i.e., the Central Range fault, interpreted by some geologists, e.g., Biq 1965; Lu and Hsu 1992; Wu et al. 2006; Shyu et al. 2008). Based on a detailed geomorophic mapping of surface traces of active faults and deformed river terraces around the Luyeh River near the southern end of the Longitudinal Valley, Shyu et al. $(2002,2008)$ indicated that there are at least seven levels of terrace risers and two major active faults accompanied with folds, corresponding to the Lichi fault and the Luyeh fault, respectively. The Peinanshan massif to the south of the
Luyeh River and the Kaotai terraces high to the north of the Luyeh River (Fig. 1) are both interpreted as products of popup structures of Pleistocene fluvial gravels in-between this two-fault system (Lee et al. 1998; Shyu et al. 2002, 2008).

From the point view of a seismic event, the recent 2006 $M_{w}$ 6.1 Peinan earthquake, which occurred in the study area, was a result from rupturing the blind west-dipping high-angle reverse fault (or the Central Range fault as mentioned above) with significant left-lateral component. This causative, but poorly mapped blind fault is located under the eastern margin of the Central Range and juxtaposes the western branch of the two-strand fault system of the LVF (Wu et al. 2006; Chen et al. 2009). Previously, Shyu et al. $(2005,2008)$ also interpreted a high-angle west-dipping re-

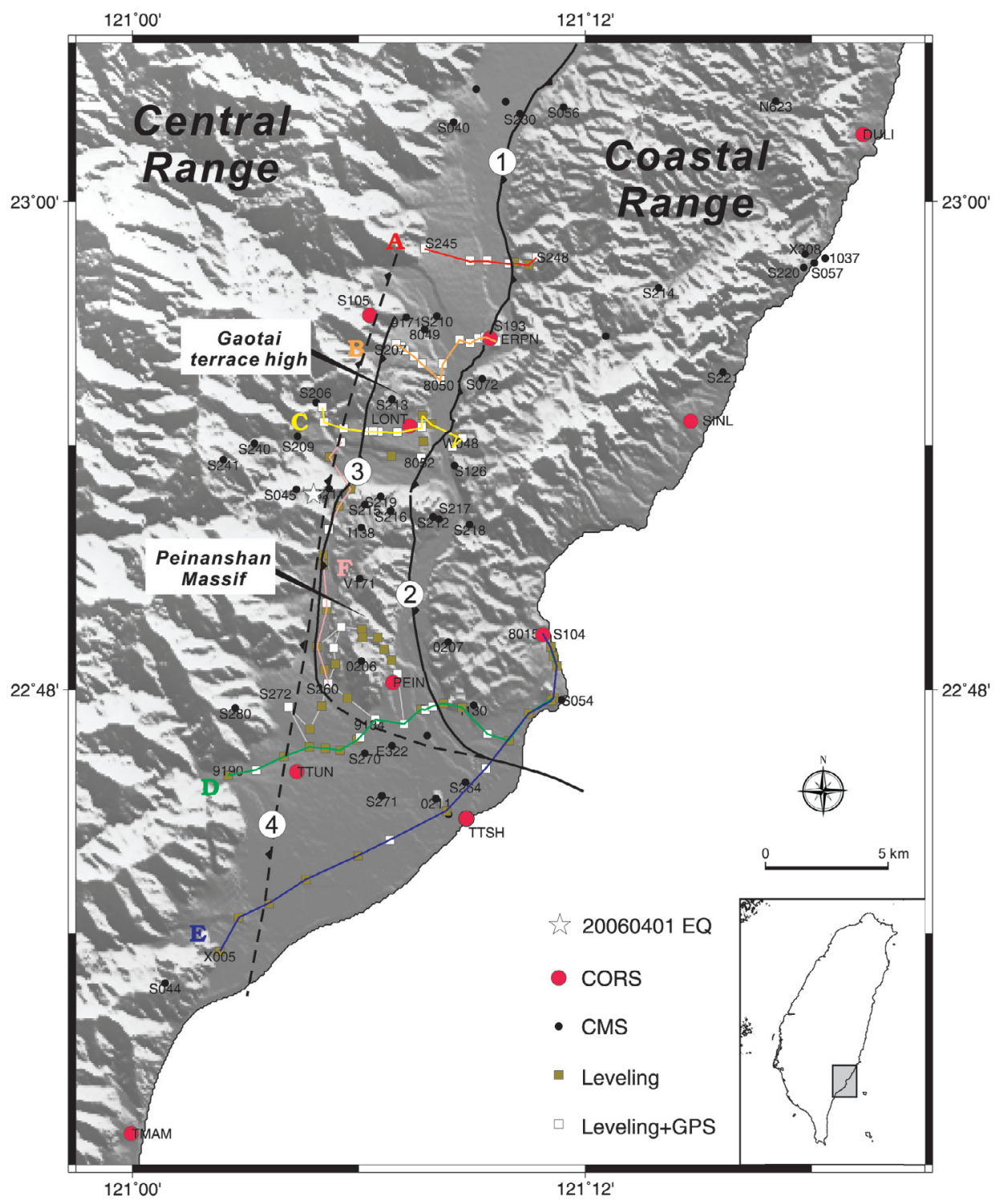

Fig. 1. Geodetic network used for analyzing vertical deformation in the southernmost Longitudinal Valley area, southeastern Taiwan. The network includes $5 \mathrm{E}-\mathrm{W}$ leveling routes (A - E) across the Longitudinal Valley, one N-S route (F) along western side of the valley, 88 campaigned GPS stations (CMS) and 10 continuous GPS stations (CORS). The occupied periods: see the text for details. Geological faults: 1, Chihshang fault, 2, Lichi fault, 3, Luyeh fault, and 4, unnamed blind fault (some called Central Range fault). 
verse fault as the geological boundary between the Central Range and the Longitudinal Valley, based on geomorphic analyses, and referred it to the Central Range fault, proposed previously by Biq (1965). However, the structural characteristics and fault kinematics of the boundary between the Central Range and the Longitudinal Valley still remain highly debatable. Several different hypotheses have been proposed over the years, a west-dipping backthrust (Biq 1965; Lu and Hsu 1992), east-dipping normal fault (Crespi et al. 1996), or a natural stratigraphic unconformity (Lee et al. 1998; Malavielle et al. 2002).

In summary, there exists three sub-parallel major active faults, including two strands of the east-dipping Longitudinal Valley fault and a west-dipping blind unnamed fault (or the Central Range fault), in the area of the southernmost Longitudinal Valley (Fig. 1). In this study we intend to better characterize the surface deformation along the southernmost LVF, in particular the vertical movement associated with these three active faults. We took advantage of the measurements of six leveling routes around the area of Luyeh County and Taitung City, some of which are carry-overs from earlier surveys for different research purposes. We conducted several repeated surveys beginning in 2002. A dense near-fault campaigned GPS network also was established in 2001 , and the numbers of stations expanded gradually in the following years. This 89-GPSstation network was also inherited and strengthened from the pre-existing array of campaign survey stations, which was installed ten years earlier in 1990 . We also integrate the nearby recently installed 10 continuous GPS stations to our campaigned surveyed network (Fig. 1).

This paper presents the results of vertical velocities derived from this 10-year-long data set of geodetic measurements in the southernmost Longitudinal Valley area. Special attention was paid to how to determine the vertical velocity for each station or benchmark, by combining two different resolutions of data, including mm-level resolution of repeated leveling and $\mathrm{cm}$-level resolution of vertical component of repeated GPS measurements. We discuss how we removed the perturbations by nearby earthquakes, particularly co- and post-seismic effects. We also discuss the relatively complex deformation pattern in the study area, including co-seismic events (on both LVF and Central Range fault), interseismic deformation, and seemingly frequent perturbations of nearby earthquakes. We thus provide not only a more complete data coverage in the entire area but also insight on short and long-term vertical deformation of the southern LV area.

\section{LEVELING MEASUREMENTS AND RESULTS}

In 2002, we started annual measurements along three east-west direction leveling routes, which are generally perpendicular to regional N-S trending major faults in the
Luyeh-Peinanshan area (Routes A, B and C, in Fig. 1). The leveling routes then prolonged eastward into the western flank of the Coastal Range the following year in 2003. In 2005, a leveling route to the south of Peinanshan and another one along the coast in the south of the Taitung area (Routes D and E in Fig. 1) have been added into our leveling network. We also conducted a N-S leveling route (Route F in Fig. 1) on the western side of the Peinanshan Massif, which had been measured three times previously in 1986, 1987 and 2001. In this study, we added a few benchmarks and conducted three repeated measurements along this $\mathrm{N}-\mathrm{S}$ route in 2006, 2007, and 2008. Hence, a total of five eastwest direction leveling routes and one $\mathrm{N}-\mathrm{S}$ route have been conducted repeatedly at least 4 years to 8 years from 2002 $-2010$.

For the field leveling survey, we adopted the first-order Class I geodetic leveling procedure (Schomaker and Berry 1981), and obeyed the double-run difference tolerances under $0.4 \mathrm{~mm}$ in a single station observation (the criteria of first-order precise leveling, Ministry of the Interior, Taiwan, 2001). The measurement difference of each leveling section between two benchmarks requires being lower than $2.5 \mathrm{~mm}$ $\times \sqrt{k}$, in which $k$ is the relative distance and unit in kilometer. The accumulated error over a few tens of kilometers is roughly estimated as about $1.0 \mathrm{~mm} \times \sqrt{k}$.

\subsection{E-W Profiles of Elevation Change}

The results of cumulative elevation change along the five E-W leveling routes from 2002 - 2009 are shown in Fig. 2. These profiles show that deformation patterns change from north to south in the LVF zone. Here, the northernmost Profile A (Rueyfong), which is located across one single fault system (the very southern end of the Chihshang Fault), revealed a significant vertical offset of $110 \mathrm{~mm}$ across the Chihshang Fault over four years, 2005 - 2009 (Fig. 2a), with an uplift rate of $20-30 \mathrm{~mm} \mathrm{yr}^{-1}$ in the hanging wall and subsidence rate of $5-6 \mathrm{~mm} \mathrm{yr}^{-1}$ in the footwall. Further south, the LVF branches into two surface strands, the Luyeh fault to the west and Lichi fault to the east. Profile B (Yongan-Rueyuan) is located at the very northern part of the two-fault system of the LVF. It illustrates a relatively rapid vertical movement across the Lichi fault from 2003 - 2008 (Fig. 2b), a total of $280 \mathrm{~mm}$ vertical offset over 5 years. Unfortunately, the leveling route was not extended westward enough to encompass the Luyeh fault. Still, we can observe a subtle anticline folding of vertical movement in the hanging wall of the Luyeh fault, showing evidence of its active behavior. We also noticed that there was substantially higher rate over 2003 - 2005 compared to 2005 - 2008, which can be interpreted as a direct co-seismic influence and afterslip of the 2003 Chengkung earthquake. Profile C (Longtien-Luyeh) shows clear vertical movements on both branches of the two faults of LVF (Fig. 2c), a total vertical 
(a) Profile A: Rueyfong

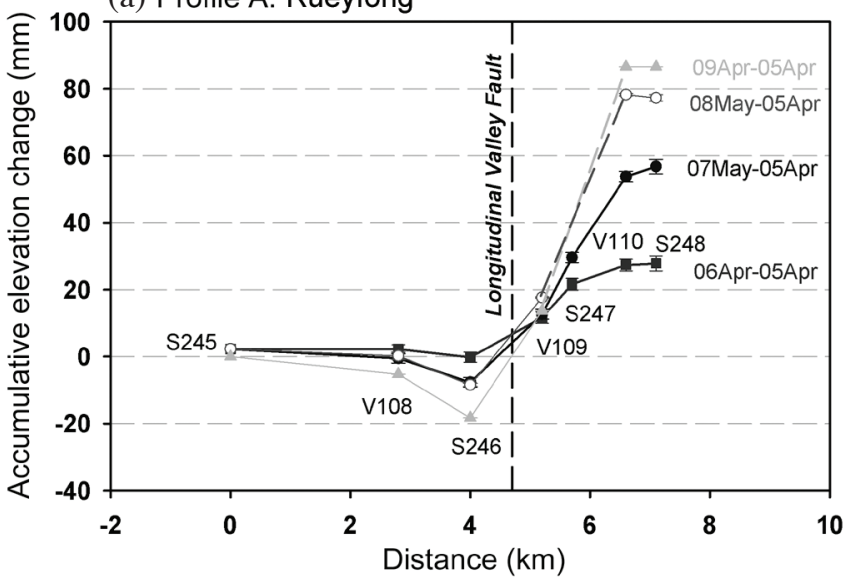

(c) Profile C: Luyeh
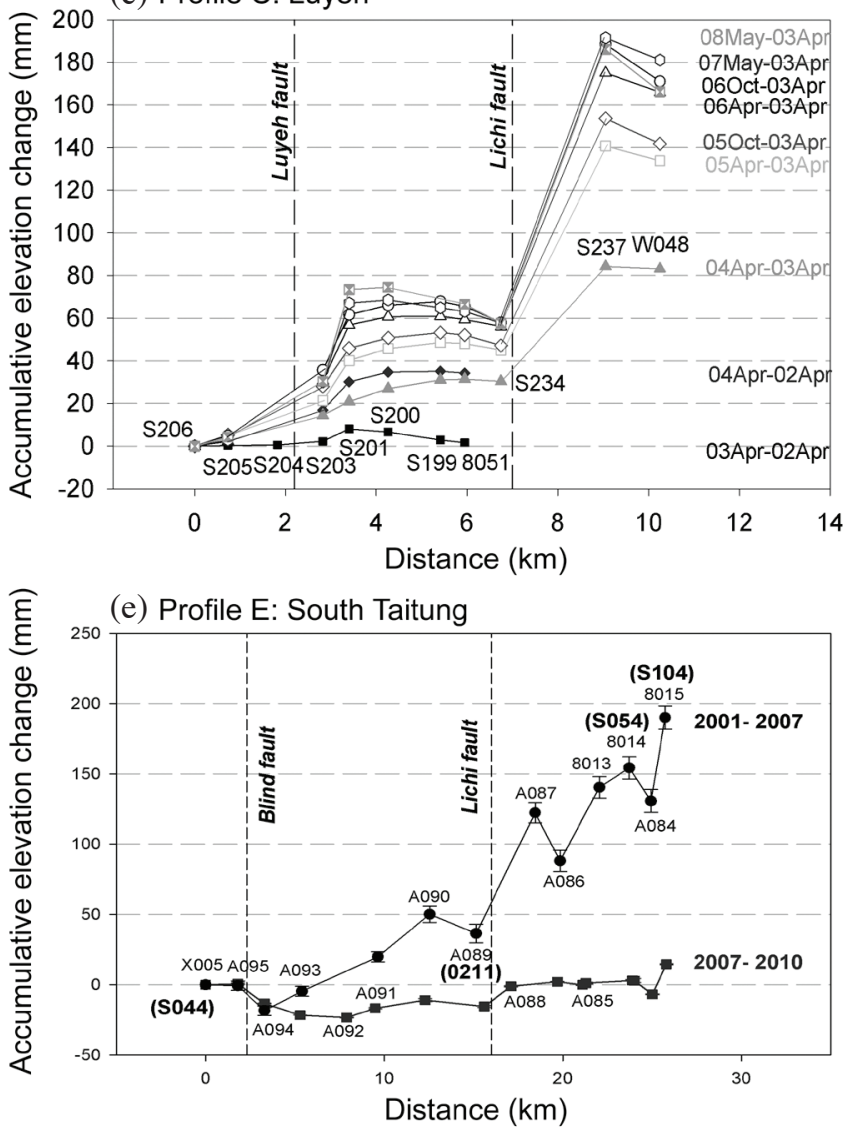

offset of $80 \mathrm{~mm}$ across the Luyeh fault and $130 \mathrm{~mm}$ across the Lichi fault in a 6-year span, 2002 - 2008. Again, higher rates over 2003 - 2005, which obviously resulted from the 2003 Chengkung earthquake, were observed. Further south, Profile D is located in the southern foot of the Peinanshan areas, where the blind west-dipping reverse fault under the Central Range (or Central Range fault) begins to play a significant role on surface deformation, together with the LVF system. The cumulative vertical movement over 2005 - 2009 indicates (1) an uplift in the Central Range with respect to the valley up to $100 \mathrm{~mm}$, which is likely associated with (b) Profile B: Yongan-Rueyuan

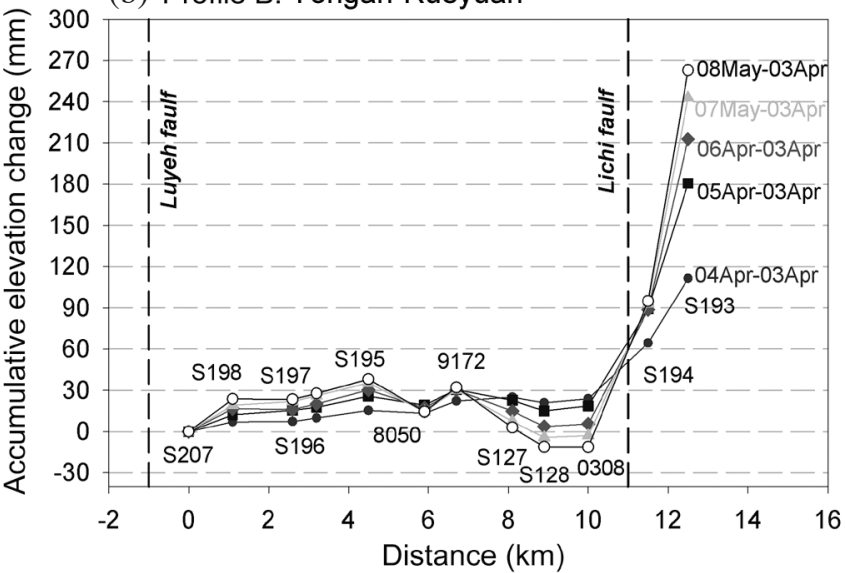

(d) Profile D: North Taitung

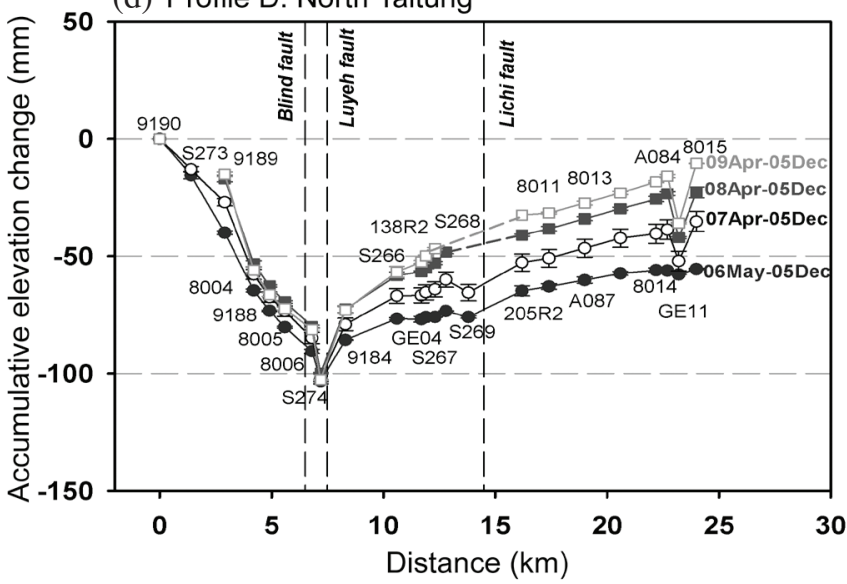

Fig. 2. Accumulative elevation changes along $5 \mathrm{E}-\mathrm{W}$ leveling routes across the southernmost Longitudinal Valley, from north to south: (a) Rueyfong (Profile A), (b) Yongan-Rueyuan (Profile B), (c) Longtien - Luyeh (Profile C), (d) Peinan (Profile D), and (e) Taitung alluvial plain (Profile E). All leveling routes were conducted from west to east and the accumulative elevation changes are calculated to be relative to the westernmost benchmark for each route. See detailed explanations in the text. co-seismic deformation of the 2006 Peinan earthquake, (2) a gradual uplift toward the east (up to $22 \mathrm{~mm} \mathrm{yr}^{-1}$ ) within the southernmost Longitudinal Valley, which seemingly can be interpreted to be associated with the two fault system of the LVF (Fig. 2d). Finally, (3) the southernmost Profile E is located along the coast in the south of the Taitung alluvial plain (Fig. 2e). It is intriguing to find that the distinct deformation patterns in the two periods between 2001- 2007 and 2007 - 2010. The elevation change from 2001 to 2007 shows a gradual uplift trend toward northeast which collectively caused an elevation change of $200 \mathrm{~mm}$ over 6 years 
across the LVF (stations from X005 to 8015). In contrast, the results of measurements from 2007 - 2010 show little vertical deformation across the valley. We shall discuss the geological interpretations later in more detail.

\subsection{Analysis of Vertical Rate Changes Through Time}

As illustrated above, the vertical deformation in the study area was substantially affected by the coseismic (possibly as well as postseismic) displacements of the two nearby large earthquakes, the 2003 Chengkung and 2006 Peinan earthquakes. In order to evaluate the secular interseismic vertical deformation, it is necessary to remove the perturbations of co- and post-seismic effects. In order to do so, we first estimate the influences of the two major earthquake events by plotting the annual elevation change rates across the active faults for every surveys compared to the precedent one along each E-W leveling profile (Fig. 3).
In Fig. 3a, we can find that Profile A in Rueyfong shows clearly different deformation rates in different periods of 2005 - 2009. The deformation rate over 2005 - 2006, which we interpret to be still influenced by post-seismic effects of the 2003 earthquake, was significantly higher than other periods from 2006 to 2009. As a result, the 2006 - 2009 results are considered to be the interseismic vertical deformation which occurred across the LVF in the Rueyfong area, which is expressed by a surface geomorphic scarp about $20 \mathrm{~m} \mathrm{high,} \mathrm{at} \mathrm{a} \mathrm{rate} \mathrm{of} 25-28 \mathrm{~mm} \mathrm{yr}^{-1}$. It is worthwhile to note that a slight, but clear subsidence can be detected in the footwall near the fault, which is in general agreement with the elastic dislocation behavior of eastdipping thrust faulting.

For Profile B in Yongan-Rueyuan of $2004-2008$ (Fig. 3b), the post-seismic effects of the 2003 Chengkung earthquake were clearly revealed during the $2004-2005$ measurements. The interseismic deformation can thus be
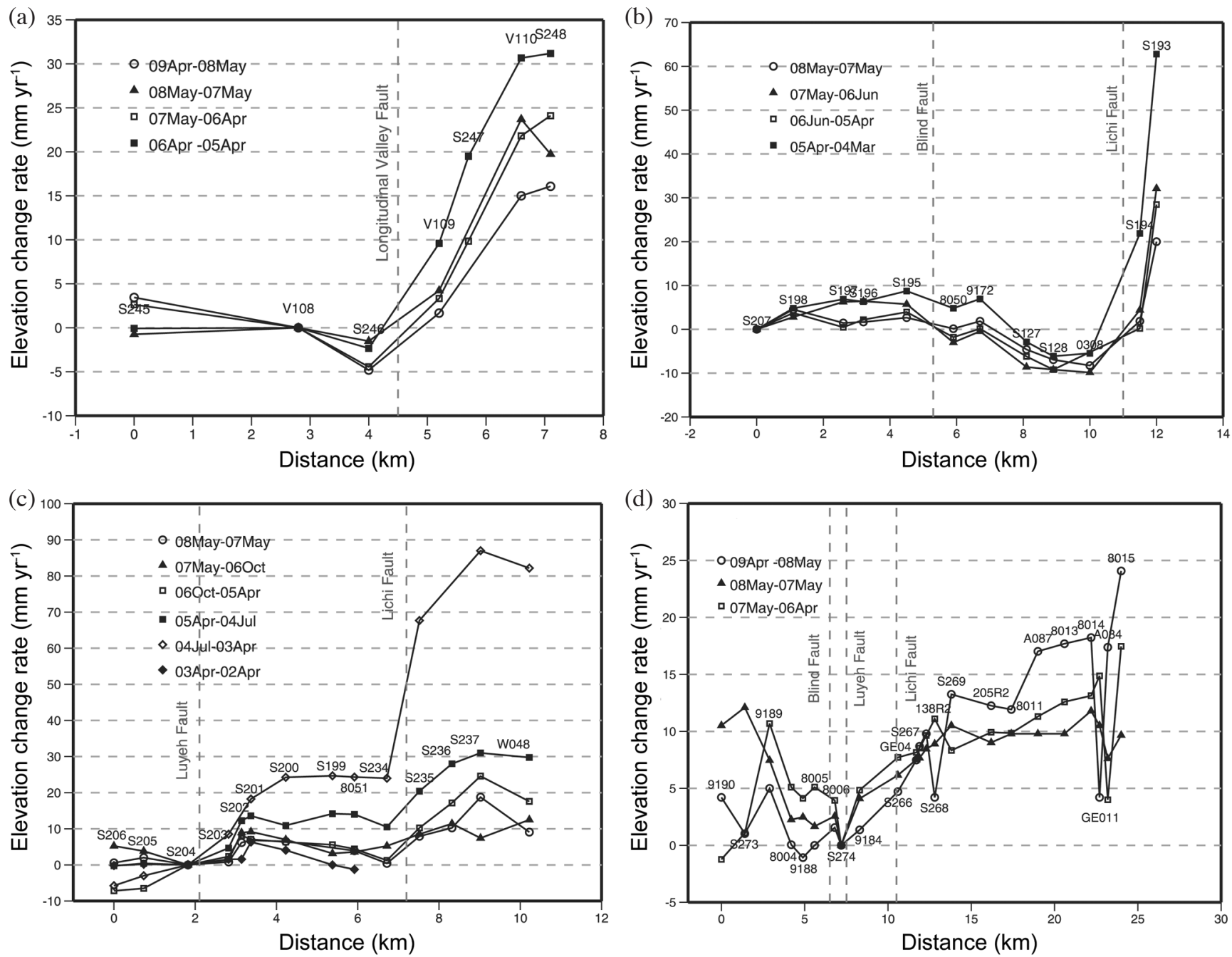

Fig. 3. Annual rate of elevation change along the four E-W leveling routes in Rueyfong (A), Rueyuan (B), Longtien (C), and Peinan (D). By identifying the periods of surveys containing co- and post-seismic influence of nearby large earthquakes, we can obtain interseismic rate of elevation changes for each leveling profile. See detailed explanations in the text. 
better defined as that which occurred over 2005 - 2008 and shows an S-shape deformation pattern on the footwall with upward thrust in the western part and a downward subsidence in the eastern part. This bulge shape on the footwall suggests that the Luyeh fault is near the western end of the leveling route. The major vertical deformation is, however, located across the Lichi fault with a $28-35 \mathrm{~mm} \mathrm{yr}^{-1}$ interseismic rate of vertical movement (stations from 0308 to S195 over 2005 - 2008).

From Route $\mathrm{C}$ in the Lungtien area, the annual rates of elevation change from 2002 to 2008 show that they were also strongly affected by the 2003 earthquake (Fig. 3c). The 2003 - 2004 deformation, which we interpret to be directly related to the co-seismic effects of the Chengkung earthquake, revealed very rapid uplift rates of 30 and $60 \mathrm{~mm} \mathrm{yr}^{-1}$ across the Luyeh and Lichi faults, respectively. In the subsequent period, 2004 - 2005, slower but still high uplift rates of 15 and $20 \mathrm{~mm} \mathrm{yr}^{-1}$ were observed, which is apparently related to the post-seismic effect of the Chengkung earthquake. As a result, we tend to define the interseismic deformation as that occurred over 2005 - 2008, which exhibits a 7 - $8 \mathrm{~mm} \mathrm{yr}^{-1}$ interseismic uplift across the Luyeh fault, and an $18 \mathrm{~mm} \mathrm{yr}^{-1}$ uplift rate across the Lichi fault (stations S234 to S237).

To the south foot of Peinanshan massif, Route D (Fig. 3d) reveals a gradual uplift from west to east across the two branches of the LVF, with a maximum uplift rate of $20 \mathrm{~mm} \mathrm{yr}^{-1}$ from 2006 - 2009. Furthermore, the gradual uplifting curve also suggests that the LVF seems to be locked in the near surface kilometers in the Taitung alluvial plain. We suspect that a sudden drop at stations A084 and GE011 may be caused by an unstable benchmark or local subsidence. As for the blind fault under eastern Central Range, although the co-seismic deformation of the 2006 Peinan earthquake can be clearly observed, we are not able to determine its interseismic rate because of its instability and limited measuring time.

In Route E (Fig. 2e), as mentioned above it is intriguing that deformation pattern changed between two periods. We tend to adopt the 2007 - 2010 results as the interseismic deformation, because it is less contaminated by the 2006 Peinan earthquake; however, the contention remains to be proved and needs further investigation.

\subsection{N-S Profile of Elevation Change}

In the N-S profile in Fig. 4, the co- and post-seismic effects, we can observe that the measurements of 2001 2006 reveal clearly these effects (presumably from the 2006 Peinan earthquake). Apart of this period, other periods of surveys (i.e., 86 - 87, 87 - 01, 06 - 07, and 07 - 08) show a similar deformation pattern, which we consider to be an interseismic deformation. As for the characteristics of the interseismic surface deformation, we find that the southern- most stations (9182 to 9179) show a slight subsidence or southward tilting.

In order to reconstruct the secular vertical field in the Taitung area, we incorporated the above results from 6 leveling routes with the GPS measurements which we describe in the next section.

\section{GPS VERTICAL MOVEMENT ESTIMATE}

\subsection{General Description and Method of Estimate}

Two types of GPS measurements were adopted for analyses in this study, a continuous observation reference station (CORS) and campaign-mode station (CMS). We used 10 continuous stations from the CORS network, which is a compilation of stations belonging to different institutions. The IESAS has installed 3 CORS in the Taitung area since 1994: S105 in the Central Range, S104 in the Coastal Range and TTSH in the Taitung alluvial plain (Fig. 1). The Central Weather Bureau (CWB) has installed 6 stations, PEIN, LONT, ERPN, DULI, TTUN and SINL since 2003, and the Ministry of Interior (MOI) has installed one station on Taimali (TMAM), 2003 and 1995, respectively.

For the campaigned GPS stations, beginning in 1989, IESAS established campaign-mode stations in a 10-year project for the breadth of the island of Taiwan ( $\mathrm{Yu}$ et al. 1997) and includes 10 stations in the Taitung area. Beginning in 2002, more than 70 stations supported by National Science Council (NSC) have been added to extend the existing monitoring network. As a result, 89 campaigned GPS stations have been used for analyzing the vertical deformation in the southern Longitudinal Valley of eastern Taiwan.

In this study, data from CORS were processed into a daily solution through the standard procedures of the Ber-

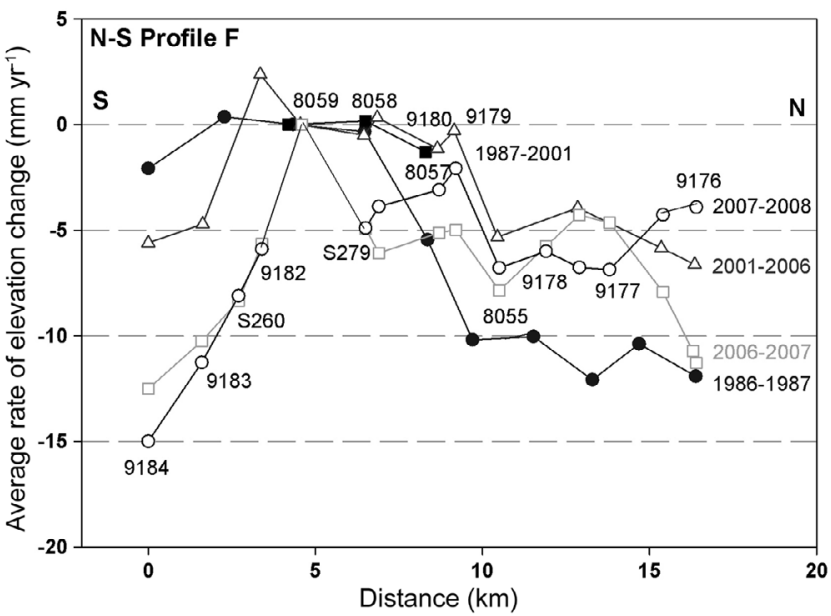

Fig. 4. Annual rate of elevation change along the N-S trending leveling route in the western side of the valley in the southern Longitudinal Valley. We also included the previous results observed by IESAS and MOI in 1986, 1987 and 2001. We reoccupied the route in 2006, 2007 and 2008. See detailed explanations in the text. 
nese V5.0 software (Dach et al. 2007). We then combined daily solutions with CMS campaign solution, using the ADDNEQ program of the Bernese software. The normal equations were used to derive a free network solution. The Paisha station (S01R) at Penghu in the tectonically stable Taiwan Strait was selected to define the "minimum constrained conditions" to its International Terrestrial Reference Frame 2000 (ITRF00) value (Chen et al. 2006). In order to better estimate the interseismic velocity, we need to remove other unexpected effects, such as earthquakes, landslides or seasonal variations. In this study we adopted the calibration function proposed by Nikolaidis (2002) to analyze the GPS time series as following,

$$
\begin{aligned}
y\left(t_{i}\right)= & a+b t_{i}+c \sin \left(2 \pi t_{i}\right)+d \cos \left(2 \pi t_{i}\right)+e \sin \left(4 \pi t_{i}\right) \\
& +f \cos \left(4 \pi t_{i}\right)+\sum_{j=1}^{n_{g}} g j H\left(t_{i}-T_{g j}\right)+\sum_{j=1}^{n_{h}} h_{j} H\left(t_{i}-T_{h j}\right) t_{i} \\
& +\sum_{j=1}^{n_{k}} k_{j} \exp \left[-\left(t_{i}-T_{k j}\right) / \tau_{j}\right] H\left(t_{i}-T\right)+v_{i}
\end{aligned}
$$

where

$a, b$ represent the linear variation of the interseismic velocity;

$c, d, e, f$ denote a year period and half year period variations;

$g$ presents the co-seismic displacement;

$h$ expresses the change rate of the velocity after the earthquake;

$k$ implies the exponential decay of the post-seismic displacement;

$H(t)$ is the Heaviside step function;

$\tau$ displays the relaxation time;

$v$ indicates the model residuals.

As can be seen in this equation, co-seismic as well as post-seismic deformation, which is quite crucial in this study, has been included in the determination for the interseismic secular velocity.

\subsection{Estimate of Vertical Velocity from Continuous GPS (CORS)}

Four earthquakes were considered to be able to produce significant perturbations to the interseismic velocity in the study area during the observation time from 1992 2010: the $1999 \mathrm{M}_{\mathrm{w}}$ 7.6 Chi-Chi earthquake, $2003 \mathrm{M}_{\mathrm{w}} 6.8$ Chengkung earthquake, $2004 \mathrm{M}_{\mathrm{w}} 6.0$ Lutao earthquake, and $2006 M_{w} 6.1$ Peinan earthquake. It is worth noting that the commonly used term "interseismic" velocity might not be totally suitable in this study. For example, three significant earthquakes occurred in an area nearby within the same ten-year time period. It is obvious that these perturbations would affect the determination of the interseismic secular velocity to some extent. As a result, it must be noted that the interseismic velocity determined from this study within this 10-year time span might be a little different than the longterm (e.g., hundreds of years) average interseismic velocity. However, for simplicity, we still use this conventional term for representing the results determinated from GPS data.

After removing the seasonal variation and the effects of the earthquakes, including co- and post-seismic events, we obtain linear trends of the interseismic vertical velocities for the 10 continuous GPS stations. They show different trends in three geological terrains: (1) slight and steady subsidence in the Central Range (Fig. 5), (2) a large variation of vertical movement, where both uplift and subsidence occurred, inside of the Longitudinal Valley (Fig. 6), and (3) a continuous uplift in the Coastal Range (Fig. 7). However, it is far from spatially homogenous within each geological terrain. Hereafter we describe the vertical velocity in each terrain in more detail.

In the eastern flank of the Central Range, station S105 reveals a steady subsidence (Fig. 5a) with an average rate of $-3.1 \pm 0.1 \mathrm{~mm} \mathrm{yr}^{-1}$ from 1994 to 2010. Further south in the Central Range, station TMAM shows a similar increasing interseismic subsidence behavior (Fig. 5b), with a slower rate of $-3.0 \mathrm{~mm} \mathrm{yr}^{-1}$ before the Chengkung earthquake and followed by significantly more rapid rates of -10.2 and -13.6 during the intervals between each major earthquake. The average subsidence rate is $-3.5 \pm 0.1 \mathrm{~mm} \mathrm{yr}^{-1}$ from 2000 to 2010 . We also notice that these four earthquakes did not contribute to significant vertical movement in the Central Range compared to the interseismic subsidence during the observed time span of 10 - 15 years.

As for the vertical deformation inside of the Longitudinal Valley, we discuss herein three continuous GPS stations: LONT, PEIN and TTUN (Fig. 6). Station LONT, which is located in the Luyeh tableland, exhibits a very slow subsidence trend with an average interseismic velocity of $-0.7 \pm 0.1 \mathrm{~mm} \mathrm{yr}^{-1}$ in $2003-2009$, after removing co- and post-seismic perturbations of a few nearby moderate earthquakes. We noticed that an unstable variation following the 2006 Peinan earthquake from 2006 to 2009, without occurrence of any significant earthquake. On the other hand, we found that the Chengkung earthquake caused an obvious co- and post-seismic perturbation at the LONT station with a vertical uplift of about $50 \mathrm{~mm}$, although the station is located a few kilometers away from the Chihshang fault, the causative fault of the Chengkung earthquake. Further south, station PEIN (Fig. 6b), located in the southeastern foot of the Peinan Massif, shows a slight constant subsidence from 2006 - 2010 with an average interseismic subsidence rate of $-4.5 \pm 0.2 \mathrm{~mm} \mathrm{yr}^{-1}$. Note that there is a $30 \mathrm{~mm}$ co-seismic downward vertical displacement caused by the 2006 Peinan earthquake. Station TTUN (Fig. 6c), located in Taitung alluvial plain also shows a slight constant subsidence from $2003-2010$ with an average interseismic subsidence rate of $-6.7 \pm 0.1 \mathrm{~mm} \mathrm{yr}^{-1}$. There are $+27,+17$, and $-4 \mathrm{~mm}$ 
co-seismic vertical displacements caused by the Chengkung, Lutao and Peinan earthquakes, respectively. It appears that the valley area is prone to significant vertical movement caused by moderate nearby earthquakes. It is also worth noting that the effects of an earthquake could either enlarge (e.g., PEIN) or diminish (e.g., TTUN) the long-term rate of vertical deformation.

With regard to vertical deformation in the Coastal Range, first station S104, near the coast in the southern Coastal Range, exhibits a relatively slow vertical interseismic uplift (Fig. 7b). We found that three earthquakes around the study area (i.e., the Chengkung, Lutao and Peinan earthquakes) caused obvious co-seismic uplift; the total collective co- and post-seismic vertical uplift reached $128 \mathrm{~mm}$. It is thus not surprising to observe the deformation for the stations in the Coastal Range, which is around the epicenter area for these earthquakes. After removing the earthquake effects, the average interseismic vertical velocity is estimated to be a slim uplift of $1.4 \pm 0.1 \mathrm{~mm} \mathrm{yr}^{-1}$ from 1994 2010. On the other hand, for station ERPN, which is located in the hanging wall near the surface trace of the LVF, the yielded interseismic velocities exhibit a trend of steady significant uplift at a rate of $8.9 \pm 0.1 \mathrm{~mm} \mathrm{yr}^{-1}$ from $2002-2010$ (Fig. 7a). The total co- and post-seismic vertical uplift of the three aforementioned earthquakes reached $122 \mathrm{~mm}$.

To summarize, according to the above analyses of the vertical velocities of CORS, we interpret the interseismic trends of the vertical movement for the three different terrains in the southern Longitudinal Valley area in this manner. The stations in the Central Range (S105 and TMAM) show a steady subsidence at a rate of -3 to $-4 \mathrm{~mm} \mathrm{yr}^{-1}$. The stations in the Coastal Range (ERPN and S104) present a

(a) $\mathbf{S 1 0 5}$

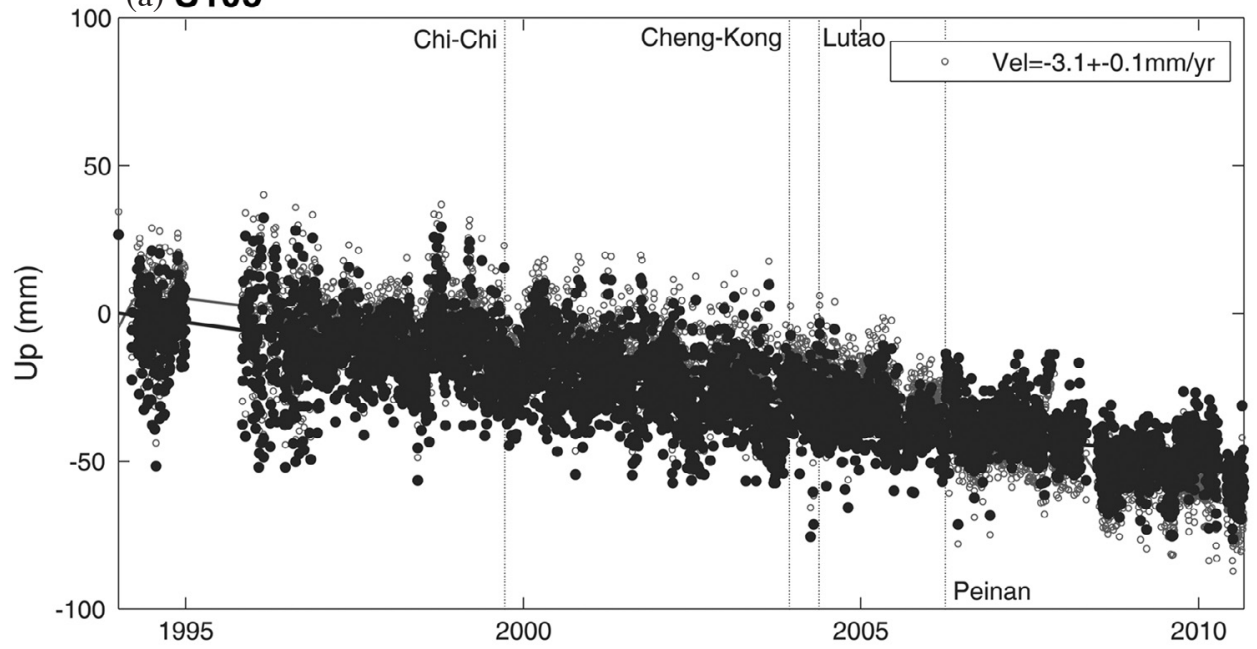

(b) TMAM

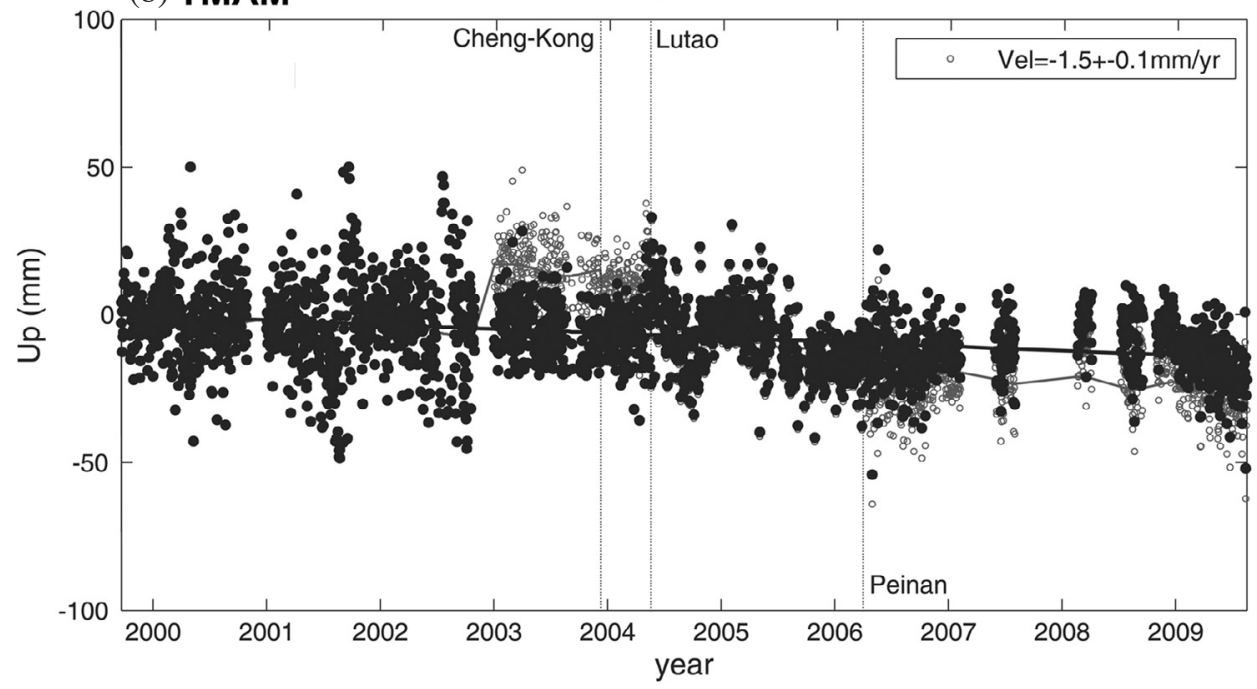

Fig. 5. Determination of GPS vertical velocity for CORS stations (a) S105 and (b) TMAM in the Central Range. The scatters are subtracted to the mean value, the $\mathrm{x}$-axis denotes the time (unit in year), and y-axis presents the relative variations (unit in $\mathrm{mm}$ ) in vertical component. Open circles in blue show the raw data and solid dots in black represent the calibrated data. The number with the uncertainty value on the right hand corner expresses the relative velocity fit by a linear trend. 


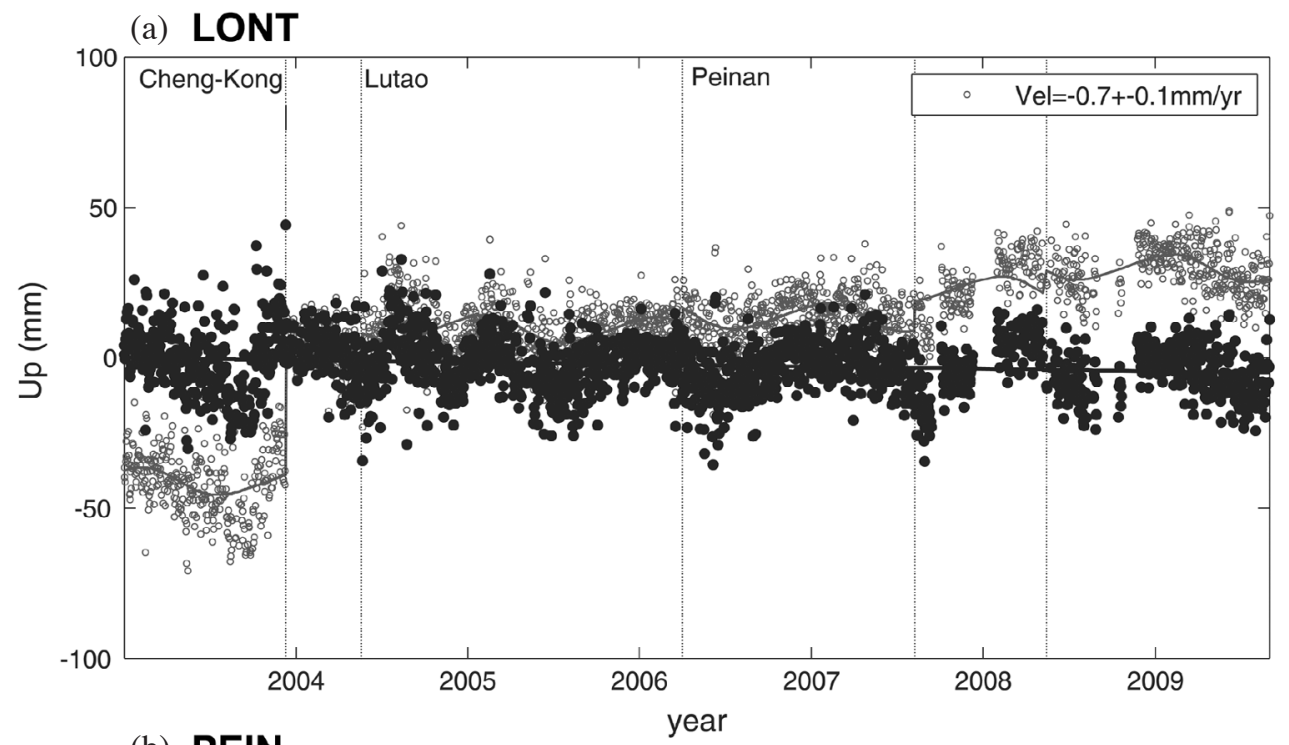

(b) PEIN

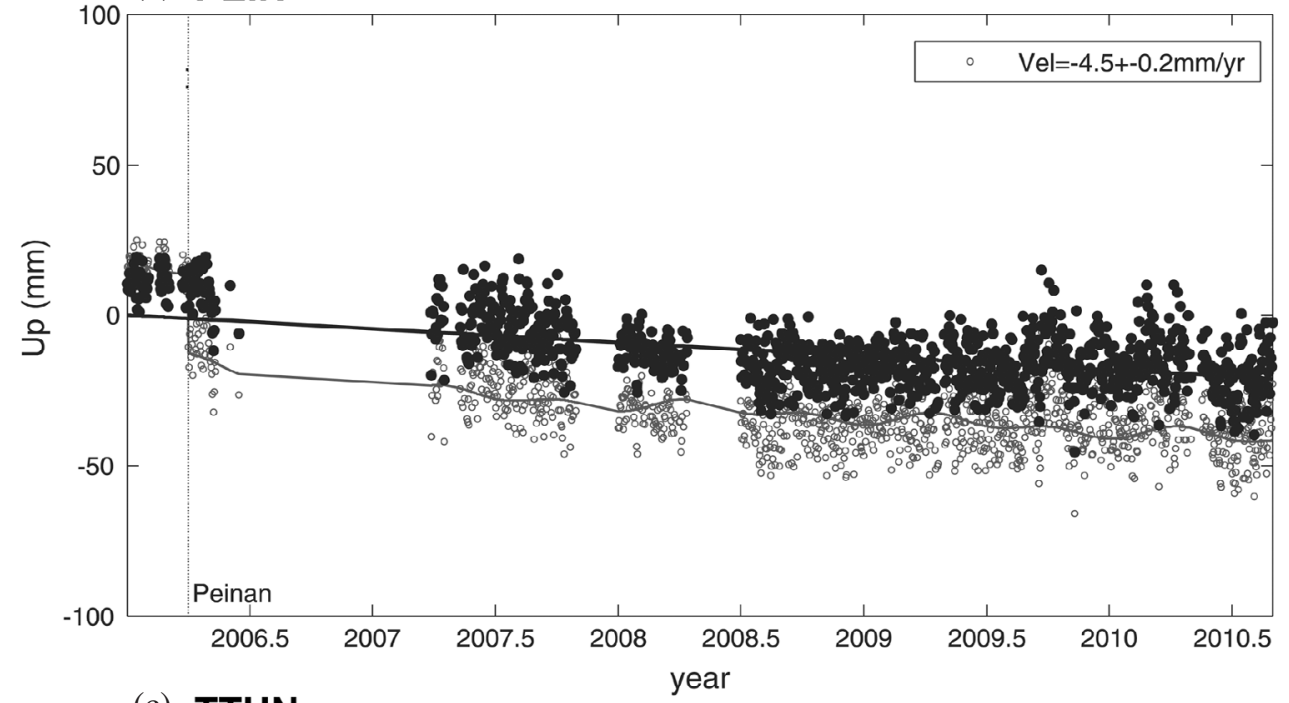

(c) TTUN

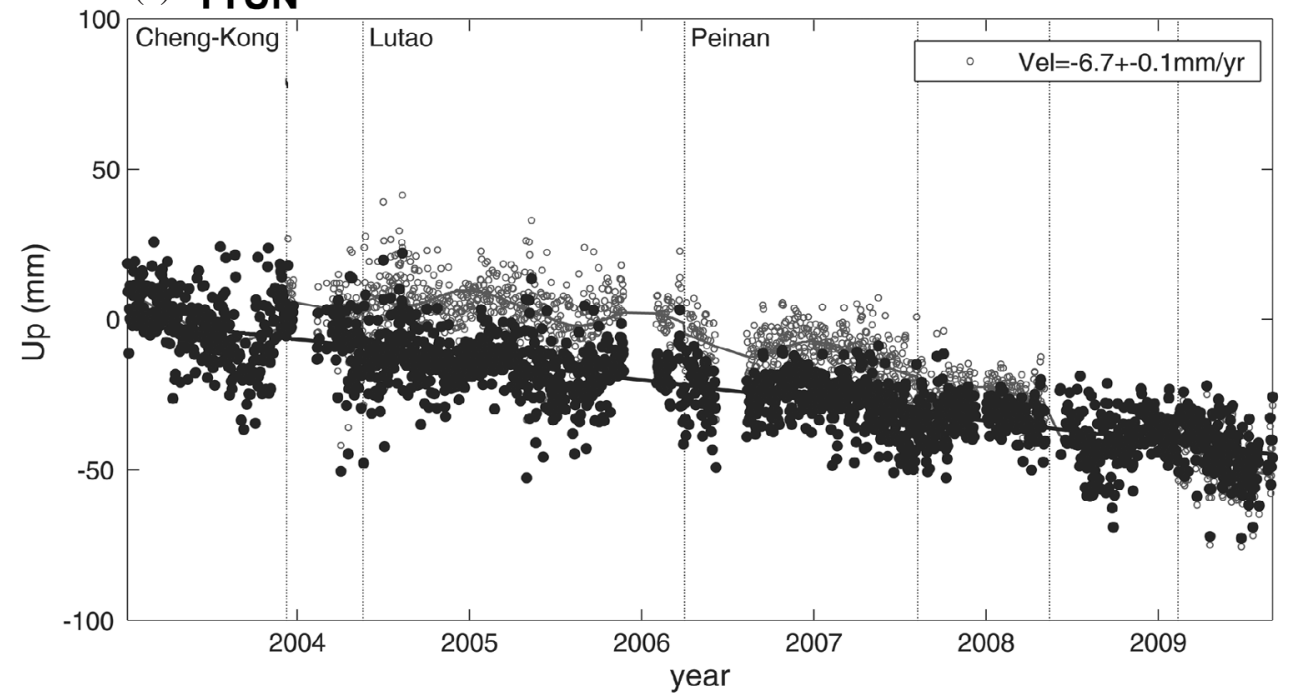

Fig. 6. Determination of GPS vertical velocity for CORS stations (a) LONT and (b) PEIN (c) TTUN within the Longitudinal Valley. Symbols: see detailed descriptions in Fig. 5. 


\section{(a) ERPN}

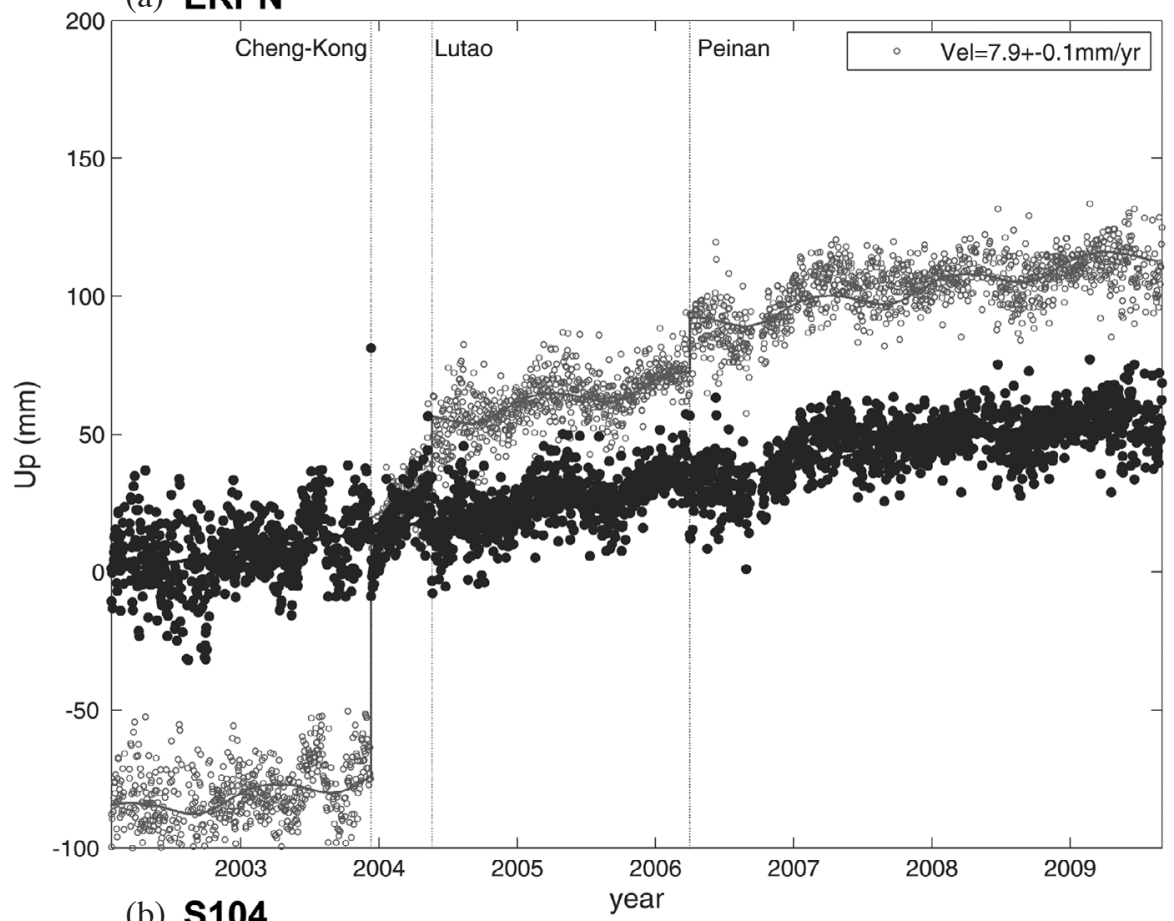

(b) $\mathbf{S 1 0 4}$

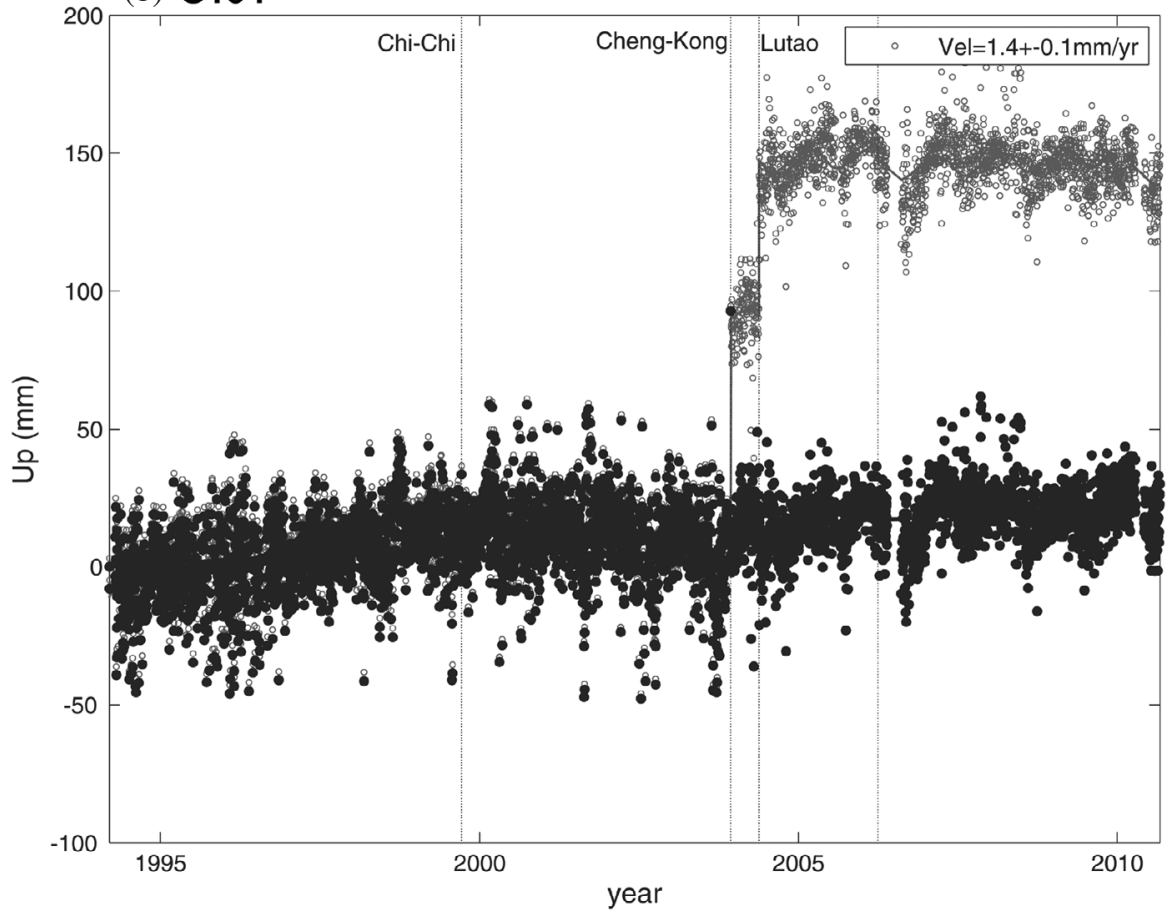

Fig. 7. Determination of GPS vertical velocity for CORS stations (a) ERPN and (b) S104 in the Coastal Range. Symbols: see detailed descriptions in Fig. 5.

slim uplift of $1.4 \mathrm{~mm} \mathrm{yr}^{-1}$ in the far-fault area and a rapid uplift of $8.9 \mathrm{~mm} \mathrm{yr}^{-1}$ in the near-fault area. The stations located within the Longitudinal Valley, such as in the Luyeh and Peinan tableland (LONT) and in the Taitung alluvial plain (PEIN and TTUN), denote a rather large variation of move-

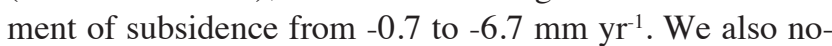

tice that the nearby earthquakes, which indeed significantly affected the vertical velocity, occurred quite frequently. It thus appears that the perturbations of local occasional moderate earthquakes have contributed substantially on the total tectonic vertical deformation in the study area. As a consequence, using conventional methods of discussing interseis- 
mic secular rates might not be sufficient for expressing the vertical deformation in the southern Longitudinal Valley. We shall discuss in more detail in the later section.

\subsection{Estimate for Campaigned GPS (CMS)}

As for estimation of the 89 campaigned GPS stations (i.e., CMS), we present 9 examples to illustrate different patterns in the three geological terrains: (1) stations S040, S045, and S044 in the Central Range (Fig. 8), (2) stations I138, 0206, and 0211 in the Longitudinal Valley (including Taitung alluvial plain) (Fig. 9), and (3) stations S056, S126, 0207 in the Coastal Range (Fig. 10). Because the CMS have been observed on a predominately annual basis, insufficient measurement bars any application in Eq. (1) for parameters estimation. We thus used a simpler formula, which only considers the linear variation of the interseismic velocity.

$y\left(t_{i}\right)=a+b t_{i}$

where $a$ and $b$ represent the linear variation of the interseismic velocity.

With regard to the effects of the earthquakes, we first removed the co-seismic jumps by calibrating the surveys immediately after the earthquakes, we then fitted the measurements in-between the earthquakes into a linear trend (Fig. 8). In order to avoid possible post-seismic influence, only the data measured one year after the earthquakes have been adopted for a linear fit. As a result, the offset of co- and post-seismic effects would be subtracted by connecting the post-seismic linear trend to the pre-seismic linear trend at the time of earthquakes.

In Figs. 8, 9, and 10, we can see that the GPS measurements are generally in good agreement with the linear fit with less than $1 \mathrm{~mm} \mathrm{yr}^{-1}$ of standard deviation after removing the co- and post-seismic perturbations of the major nearby earthquakes. We also found that the behavior of recorded station velocities in these three different geological terrains generally are consistent with those derived from the CORS. For interseismic vertical movement, the eastern edge of the Central Range shows a steady and slow subsidence (Fig. 8). The Longitudinal Valley reveals a variation of movement including both a slight uplift and subsidence (Fig. 9). The Coastal Range exhibits uplift with either a slow rate (far fault) or a rapid rate (near fault). These behaviors are generally consistent with those derived from 10 continuously monitoring GPS stations.

More closely, a slow subsidence of $-10.6,-2.5$ and $-9.9 \mathrm{~mm} \mathrm{yr}^{-1}$ can be found in the Central Range for the stations S040, S045 and S044, respectively (Fig. 8). Within the valley, the stations located on the Peinan Massif show a slight uplift with average rates of 3.2 and $2.8 \mathrm{~mm} \mathrm{yr}^{-1}$ for I138 and 0206, respectively (Figs. 9a and b); station 0211 on the Taitung alluvial plain shows a slight subsidence of $-3.3 \mathrm{~mm} \mathrm{yr}^{-1}$ before the 2006 Peinan earthquake (Fig. 9c), but accelerates to a rapid subsidence of $-25 \mathrm{~mm} \mathrm{yr}^{-1}$ following the earthquake, revealing a strong influence by the Peinan earthquake. This also indicates that the post-seismic effect of the Peinan earthquake on the Taitung plain is longer than we originally expected. Finally the stations in the Coastal Range show a slow far-fault uplift of $1.8 \mathrm{~mm} \mathrm{yr}^{-1}$ for station S056 and $0.1 \mathrm{~mm} \mathrm{yr}^{-1}$ for station 0207 (Figs. 10a and c), and a rapid near-fault uplift of $15.8 \mathrm{~mm} \mathrm{yr}^{-1}$ for station S126 (Fig. 10b).

With regard to co- and post-seismic effects, the 1999 Chi-Chi earthquake appeared to produce a more significant effect in the eastern margin of the Central Range than in the Coastal Range. On the other hand, the nearby earthquakes, such as the 2003 Chengkung and the 2006 Peinan earthquakes, showed substantial effects on all three different terrains. For instance, the Chengkung earthquake caused obvious co-seismic vertical displacements of 94, 103 and $66 \mathrm{~mm}$ in Coastal Range stations (S056, S126, 0207) and less but still significant amounts of 49,29 and $28 \mathrm{~mm}$ at stations S040, S045, S044, respectively, in the Central Range. Regarding the Peinan earthquake, it induced upward motion in the eastern Central Range, and slight uplift but substantial downward motion in the northern and southern Longitudinal Valley, respectively.

\section{VERTICAL VELOCITY FIELD: COMBINATION OF LEVELING AND GPS}

In this study, we followed precise leveling criterion during each field measurement. In the case of the southern Longitudinal Valley, we can assume an accuracy within millimeters in relative height between leveling benchmarks. After several repeated measurements, the velocities for each benchmark can be estimated by a linear fit, by excluding the periods of occurrence of the aforementioned earthquakes. The results show that the yielded velocities have a generally small standard deviation of about $1.5 \mathrm{~mm} \mathrm{yr}^{-1}$ (Fig. 11).

As mentioned above, for GPS height determinations, we used station S01R as the reference station which shows a very stable and slow movement of $-0.8 \pm 0.0 \mathrm{~mm} \mathrm{yr}^{-1}$ over the $1991-2010$ period on the ITRF00 coordinate system (Kuo 2010). As a result, the vertical change rates of GPS heighting in the study area would also be attached to the ITRF00 coordinate system. After discounting the effect of co- and post-seismic displacements as described above, the vertical interseismic GPS velocities can be acquired.

In order to combine the leveling results with the GPS results, we tend to adopt station $\mathrm{S} 104$ as a common reference which is not only a CORS station but also very close to a leveling benchmark 8015 . Thanks to a 16 -year-long period of data (same as S01R since 1994) and a clear sky environment, we are rather comfortable that the station can 

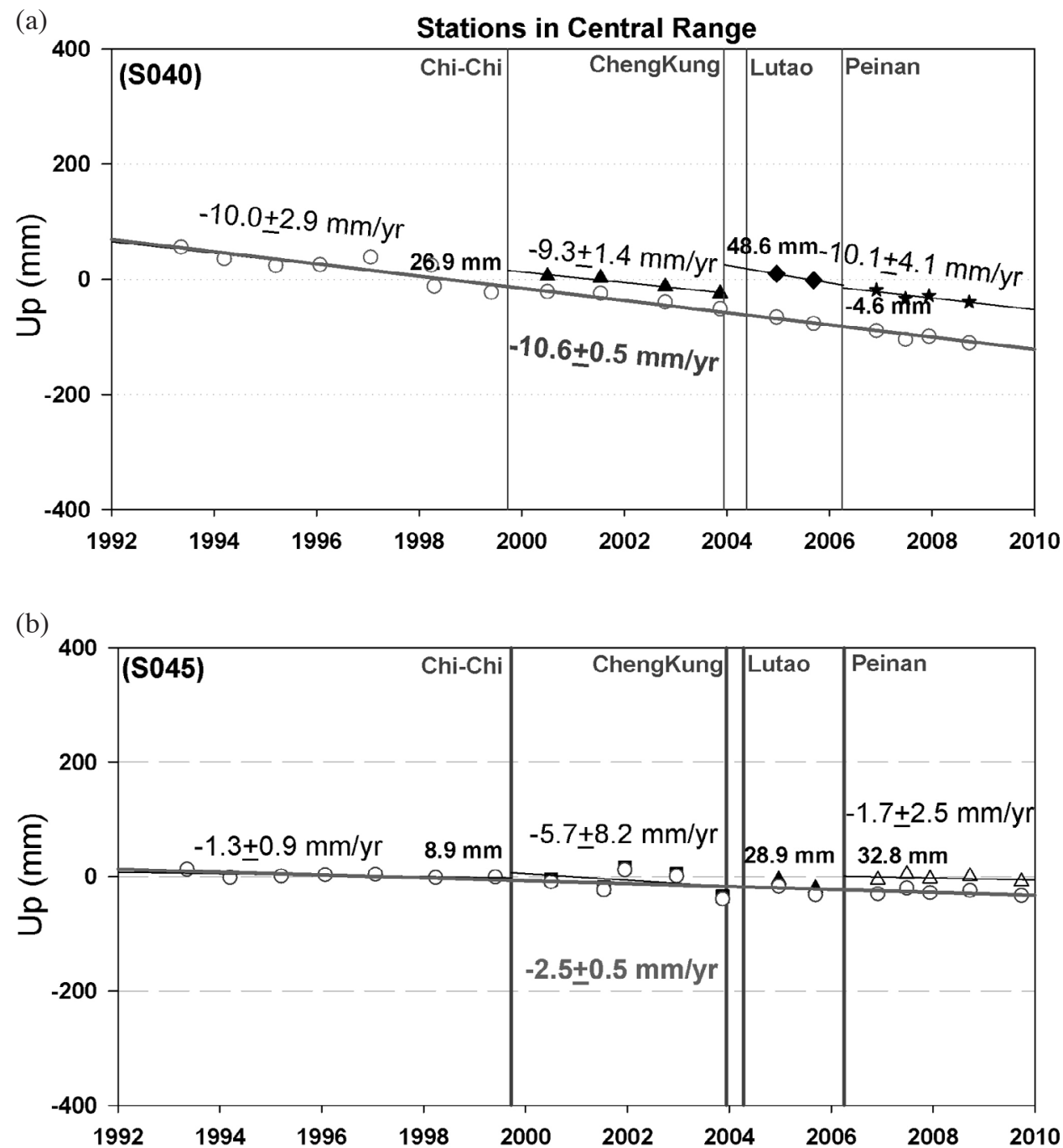

(c)

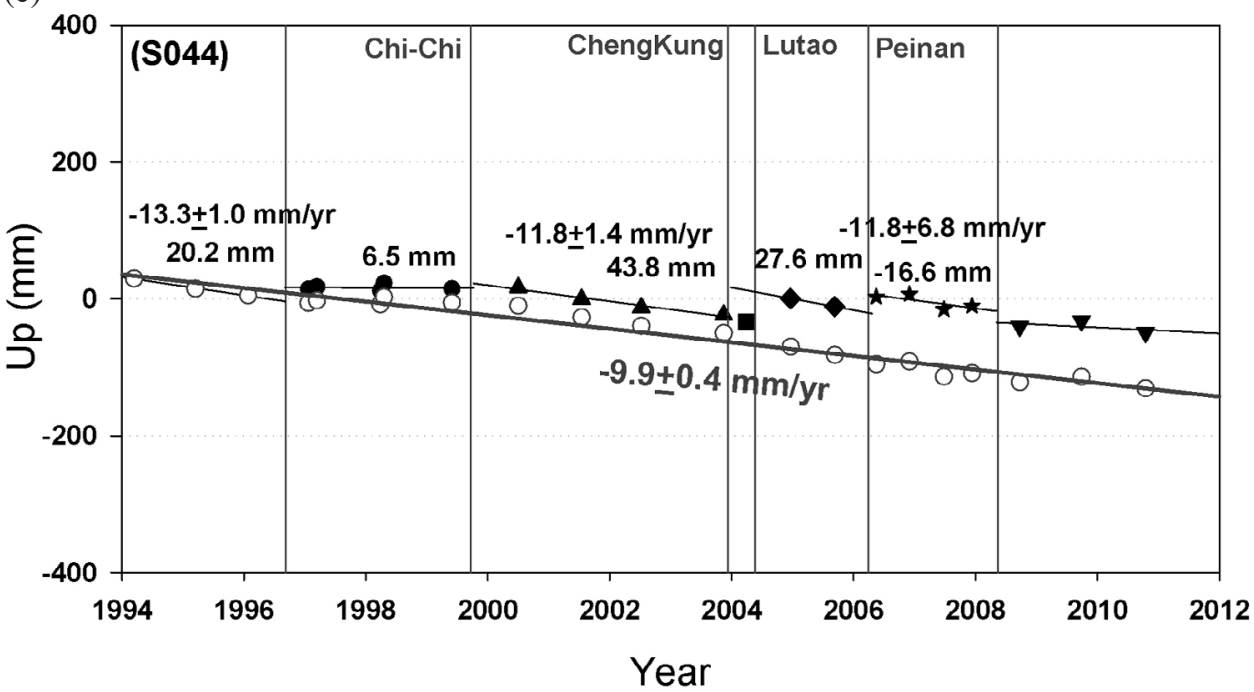

Fig. 8. Campaigned GPS time series (black marks) and calibration after removing the earthquake effects (pink circles) for three stations (S040, S045 and S044) in the eastern flank of the Central Range. The GPS interseismic vertical velocities, which were obtained by linear fits, are expressed by the numbers with uncertainty. The numbers without the uncertainty value indicate the relative co-seismic displacements of the corresponding earthquakes. 

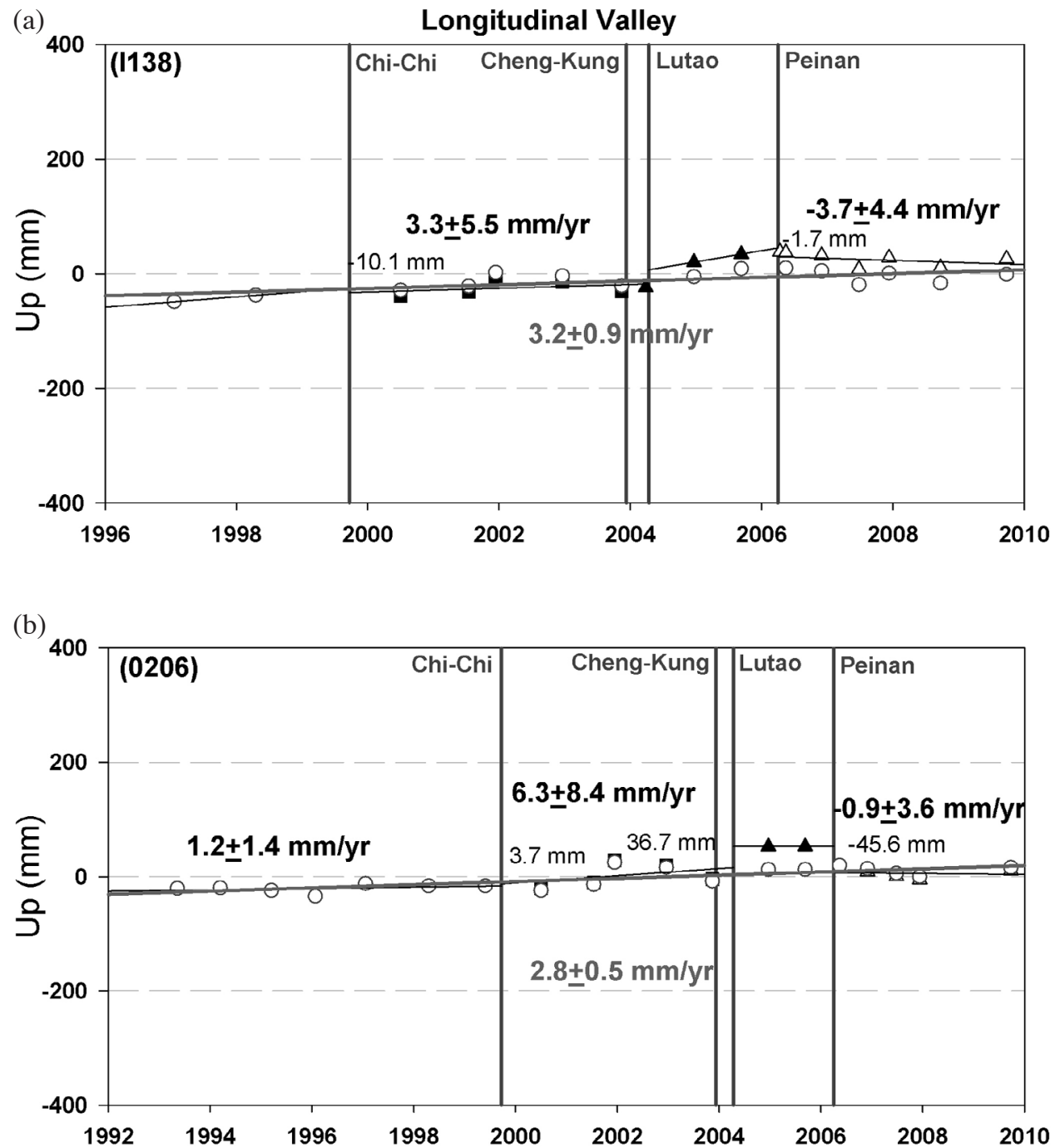

(c)

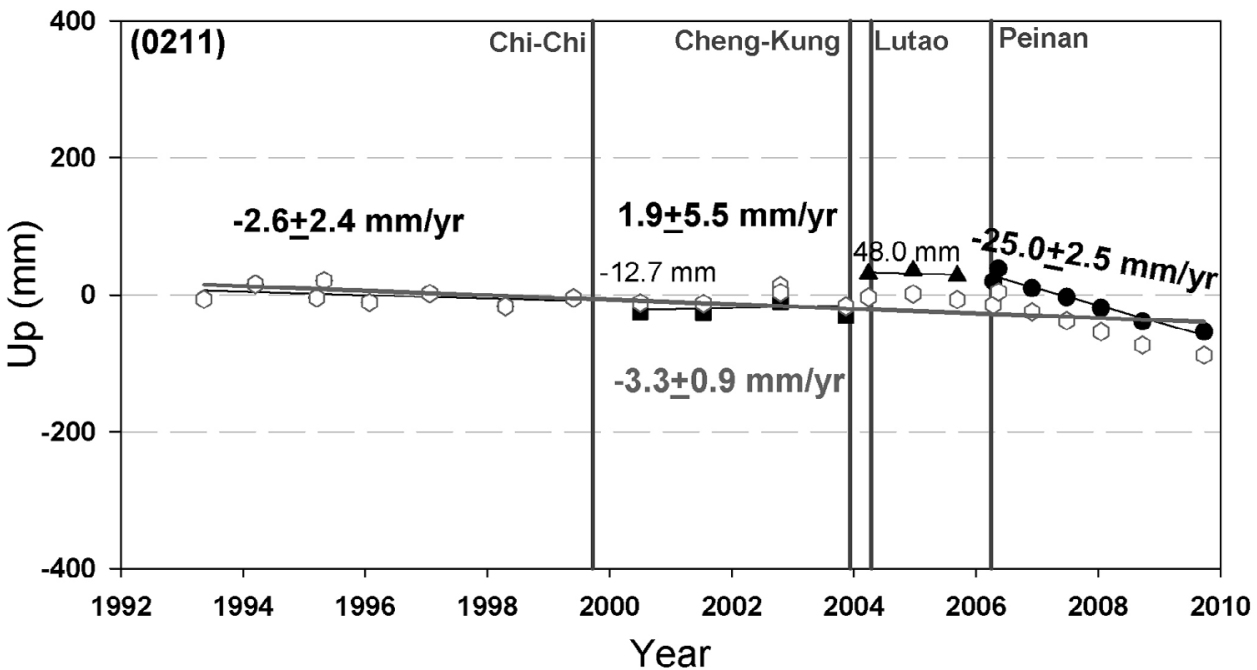

Fig. 9. Campaigned GPS time series (black marks) and calibration after redacting earthquake effects (pink circles) for three stations (I138, 0206 and 0211) inside the Longitudinal Valley. Symbols: see Fig. 8 for further detailed descriptions. 

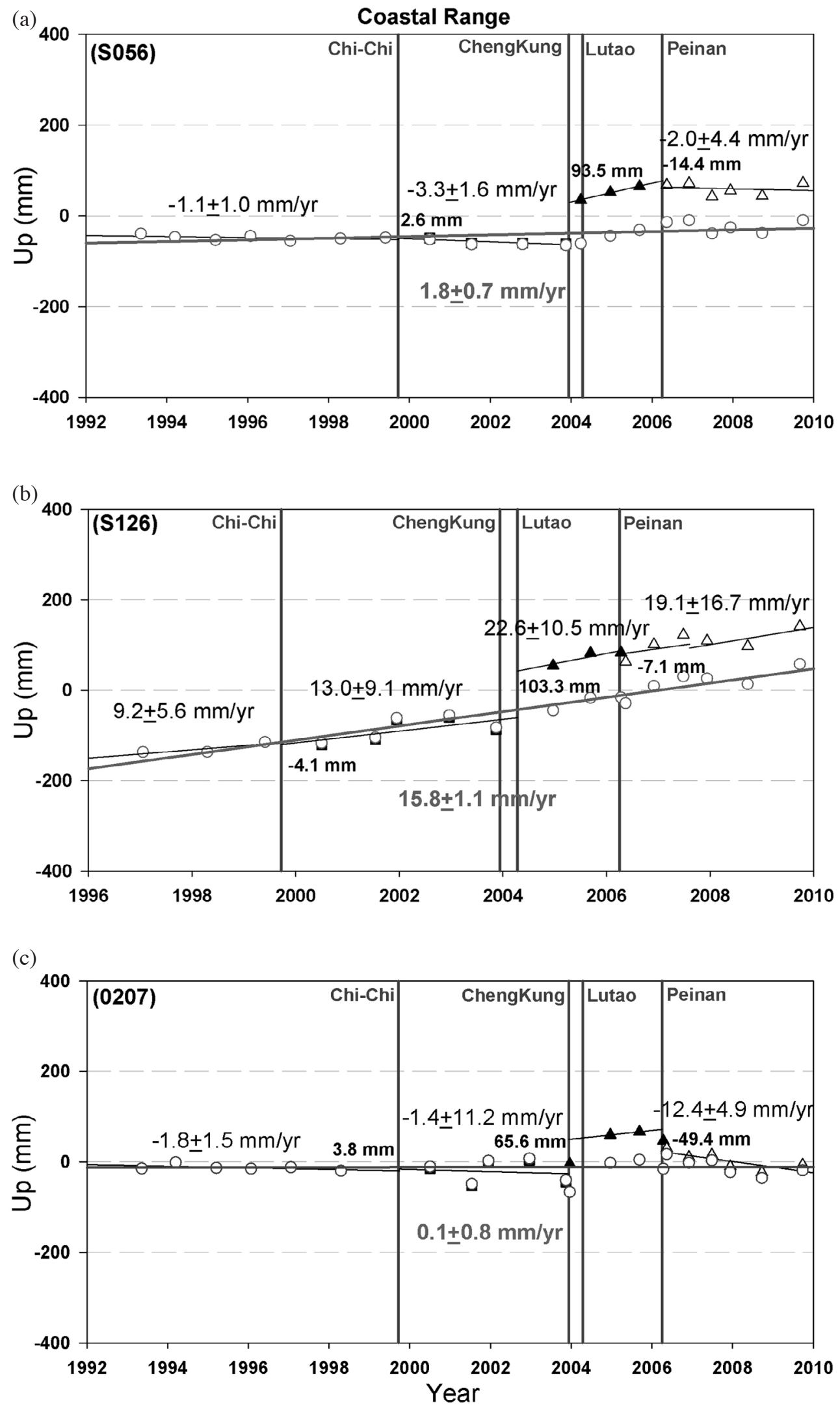

Fig. 10. Campaigned GPS time series (black marks) and calibration after redacting earthquake effects (pink circles) for three stations (S056, S126 and 0207$)$ in the Coastal Range. Symbols: see Fig. 8 for further detailed descriptions. 

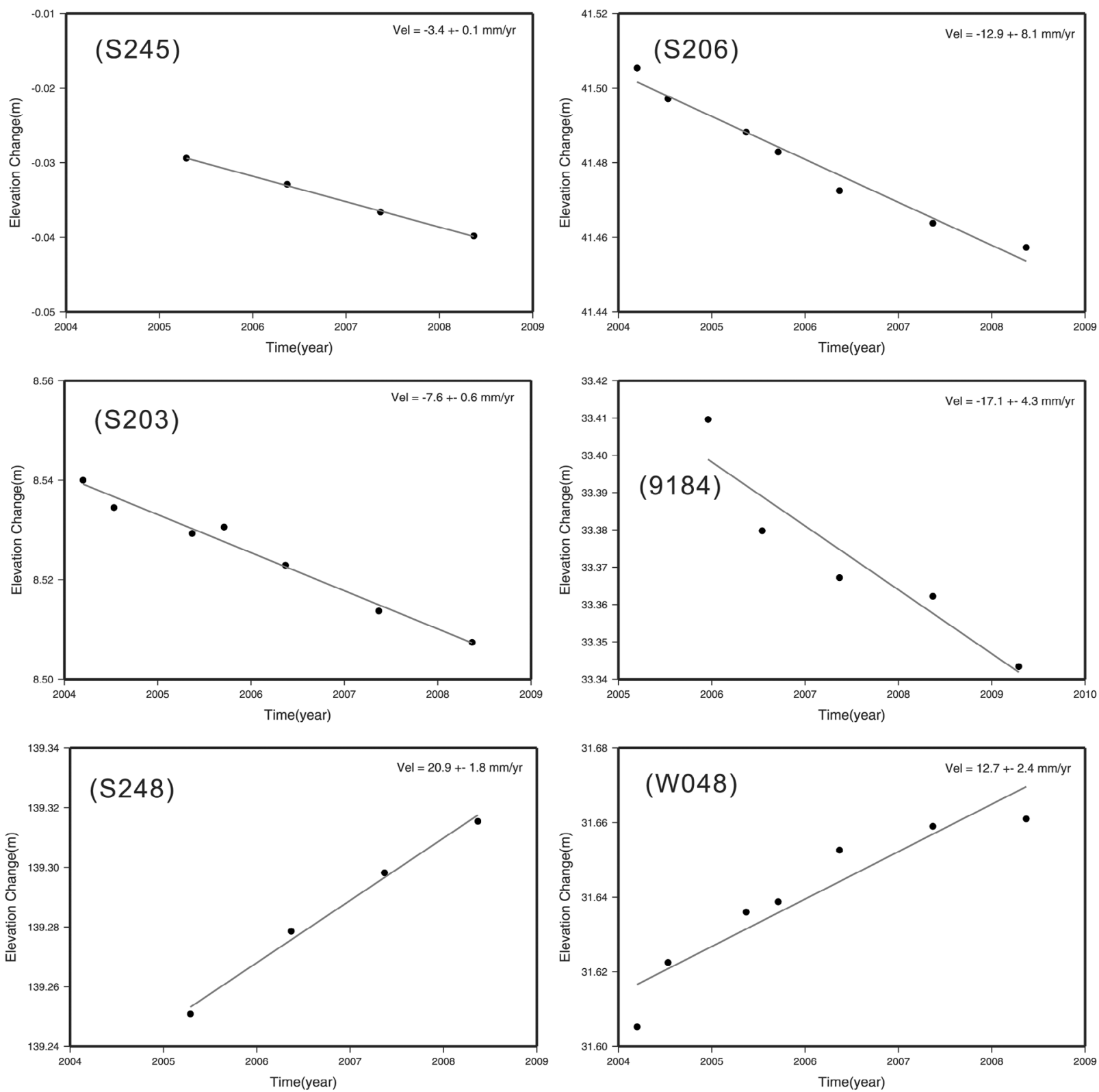

Fig. 11. Examples of time series and linear fits of calibrated leveling measurements for three different geological terrains in the study area. Upper graphs (S245 and S206): the stations in the Central Range; middle graphs (S203 and 9184): stations in Longitudinal Valley; lower graphs (S248 and W048): stations in the Coastal Range. The earthquake effects have been redacted by excluding the periods with possible co- and post-seismic influence. See details in the text.

furnish reliable vertical result. In addition, S104 exhibits little vertical motion and shows a relatively stable interseismic trend with a slim uplift rate of $1.4 \mathrm{~mm} \mathrm{yr}^{-1}$. In practice, we assigned a velocity of $1.4 \mathrm{~mm} \mathrm{yr}^{-1}$ at GPS station S104 to the neighboring leveling benchmark 8015 . The velocities for all the remaining leveling benchmarks are calibrated to benchmark 8015. We defined three categories of stations including all the leveling and GPS stations. The stations of category I are only measured by GPS surveys without leveling measurement, but provide stable, long-term mainte- nance and a good sky view, hence the GPS heighting can be acquired from GPS observations. The second type of stations (category II) was occupied by leveling surveys only. The third category of stations is occupied by both GPS and leveling measurement instruments. 44 stations out of 88 belong to category III which give both GPS heighting and precise leveling results. Hence we apply different weights with an inverse proportion of standard errors to adjust the results. The results showed that the weights on the leveling data are usually about three times than those on the GPS heighting. 
Finally, we utilized a map of the leveling-GPS vertical "interseismic" velocity field in the southernmost Longitudinal Valley (Fig. 12, Table 1). The vertical velocity field reveals a few interesting deformation characteristics in the study area. First, the most dominant interseismic uplift (about $30 \mathrm{~mm} \mathrm{yr}^{-1}$ ) is located in the western Coastal Range, corresponding to the overthrusting of the Coastal Range along the Lichi fault (and also the southern end of the Chihshang fault) against the km-thick Peinan massif inside the Longitudinal Valley; however, the Coastal Range shows a smaller amount of interseismic uplift toward the east and toward the south in Taitung City. A plausible possibility is that the Lichi fault becomes more of a strike-slip than thrust in the south which agrees with the trend of fault appears to turn to a WNW direction in its southern end (Fig. 12). Indeed, the GPS interseismic horizontal displacements favor the latter scenario (Chen et al. 2011). A recent study taken from bathymetric geomorphic features also suggests a sharp E-W turn of the LVF in the offshore area east of Taitung (O'hara et al. 2011). Secondly within the Longitudinal Valley, the Peinan massif and the Lungtien-Gautai terrace high exhibit an unstable interseismic movement, either uplift or small subsidence in the middle section (from -10 to $5 \mathrm{~mm} \mathrm{yr}^{-1}$ ), with an increasing trend of subsidence toward north and south. Beyond the Peinan massif and Gautai terrace high, an alluvial plain of the valley exhibits significant subsidence from -5 to $-25 \mathrm{~mm} \mathrm{yr}^{-1}$ which we attributed to the footwall subsidence of the thrusting LVF, although the human effect of groundwater pumping cannot be completely ruled out. Finally the eastern flank of the Central Range shows slight interseismic subsidence with a lateral variation from north to south. Conversely, the relative vertical motion between the eastern Central Range and the Longitudinal Valley appears to be subtle and is not consistently homogenous in the study area.

In sum, we tend to interpret the interseismic vertical deformation in the southernmost Longitudinal Valley area is primarily accommodated by fault creep on two strands of the LVF (the Luyeh fault and the Lichi fault) and associated surface folding. Another major fault in the area, the blind west-dipping fault under the eastern margin of the Central Range (i.e., the so-called Central Range fault) proved to be less revealing with regard to the interseismic vertical deformation. The high-range topography in the Central Range is not reflected by the slow subsidence interseismic trend revealed by our results thus suggesting other mechanisms, such as co-seismic events, are responsible for this long-term deformation.

\section{DISCUSSION}

\subsection{Discrepancy Between GPS and Leveling}

By comparing the calculated vertical velocities of precise leveling and GPS heighting at 44 stations with both measurements (Fig. 13 and Table 2), we found that most of the stations are of the same moving trend between the two results, and most of the differences are less than $\pm 10 \mathrm{~mm} \mathrm{yr}^{-1}$. From Table 2, we can find that the average uncertainty is 1.6 and $1.8 \mathrm{~mm} \mathrm{yr}^{-1}$ for leveling and GPS heighting, respectively.

Considering the nature that the velocity of precise leveling is computed by the relative differences between benchmarks with respect to the benchmark 8015 near the CORS S104, as a result, in addition to the accuracy of the measurement, the farther it is from reference station 8015 the larger the uncertainty of the leveling velocity. This might explain why the stations in the northern part of the study usually have larger differences between GPS and leveling determinations. We also found that some near-fault stations, for instance, campaigned GPS stations S193 and W048 show higher variations of calculated velocities. We interpret this to be due to an acceleration of the velocity following the Chengkung earthquake (i.e., post-seismic effect). Similar movement behavior can be found at CORS station ERPN (Fig. 7a), which is located at the hanging wall near the LVF. The campaigned GPS stations, 8050, 8058 and 9176, located in the north of the Peinanshan Massif denote larger variations of velocity uncertainty as affected by the rapid post-seismic surface creep of the Peinan earthquakes. Similar movement behavior can be found in CORS station LONT (Fig. 6a).

We thus conclude that these post-seismic accelerations of velocity indeed affected our determinations of interseismic vertical velocity, and were the main sources of the uncertainties. As a result, although the accuracy of precise leveling measurements is rather good in each survey, the average rates of stations are still affected by the different magnitude of post-seismic movement which is difficult to be completely accounted for campaigned leveling and GPS measurements. The average uncertainty of precise leveling is estimated to be $1.3 \mathrm{~mm} \mathrm{yr}^{-1}$ which is considered minor compared to the interseismic rate in this area.

\subsection{Effects of Nearby Earthquakes on Long-Term Defor- mation}

As discussed above, moderate earthquakes frequently occurred around the study area of the southernmost Longitudinal Valley. More importantly, they seem to contribute substantial vertical surface deformation (as well as horizontal deformation which we shall discuss in a separate paper) on top of the sum of the "interseismic secular deformation" and the "co- and post-seismic deformation." Over the last ten years, two moderate neighboring earthquakes showed this kind of effect, the $2003 \mathrm{M}_{\mathrm{w}} 6.8$ Chengkung earthquake and $2004 \mathrm{M}_{\mathrm{w}}$ 6.0 Lutao earthquake (the 2006 M 6.1 Peinan earthquake is considered as one of the major co-seismic events for the area). The southernmost Longitudinal Valley 
area seemingly does not fit well with the general case that long-term deformation is represented by the sum of interseismic and co-seismic (including post-seismic) deformation. Here, long-term deformation analyses should consider additional frequent perturbations of nearby moderate to large earthquakes.

Hereafter we discuss nearby earthquakes effects on three major geological terrains, the eastern Central Range, Longitudinal Valley and Coastal Range. First, for the eastern Central Range, the nearby two earthquakes showed little effect on the vertical movement. In contrast, the 1999 ChiChi earthquake, which is a far-field but quite large earthquake, likely produced visible effects including co-seismic and long-term post-seismic deformation, at least to some extent. However, because few stations in the study area provide adequate time coverage, it is difficult to draw a concrete conclusion with regard to the contributive effects from the Chi-Chi earthquake. On the other hand, the 2006 Peinan earthquake, which ruptured from one of the three major faults in the southern Longitudinal Valley area, indeed produced significant upward co-seismic motion to compensate the slight interseismic subsidence.

Second, within the Longitudinal Valley, the two nearby earthquakes produced relative upward motion with respect to the interseismic secular trend. For instance, the 2003 Chengkung earthquake revealed an uplift of about $50 \mathrm{~mm}$

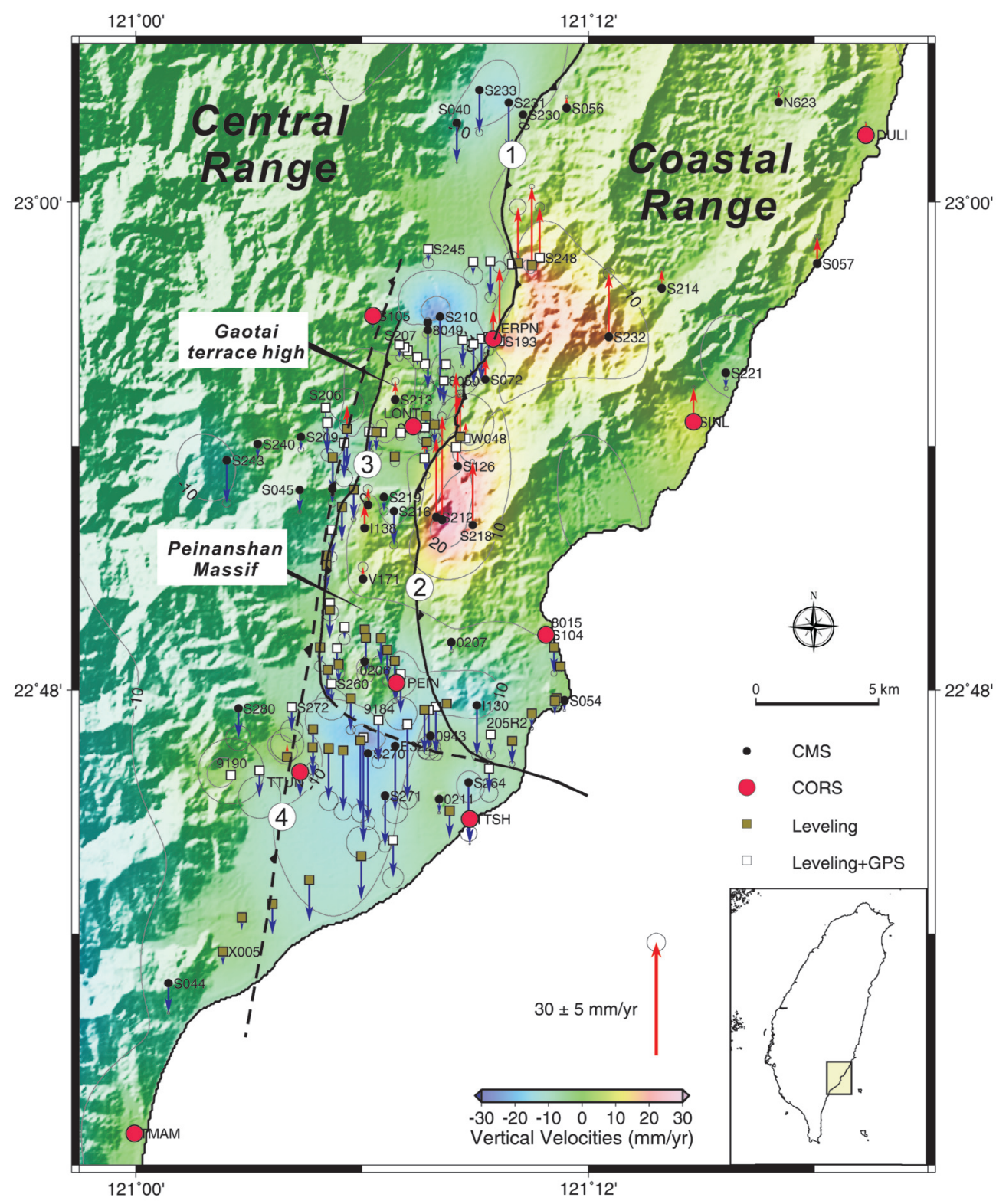

Fig. 12. Color-coded interseismic vertical velocity field with contours in the southernmost Longitudinal Valley, southeastern Taiwan. The reference point is the GPS station S01R at the Penghu island in the Taiwan Strait. The results are based on analyses of combined leveling and GPS heighting. See text for detailed explanations and geological interpretations. 
Table 1. Vertical velocity field in southeastern Taiwan.

\begin{tabular}{|c|c|c|c|c|}
\hline Station & Lon & Lat & $\begin{array}{c}\text { Velocity } \\
\left(\mathbf{m m} \mathbf{y r}^{-1}\right)\end{array}$ & Type \\
\hline 0206 & 121.1012 & 22.8117 & $1.0 \pm 0.8$ & CMS \\
\hline 0207 & 121.1395 & 22.8196 & $-2.3 \pm 0.9$ & CMS \\
\hline 0211 & 121.1340 & 22.7552 & $-3.6 \pm 0.7$ & CMS \\
\hline 0308 & 121.1528 & 22.9440 & $-11.5 \pm 1.2$ & CMS+Leveling \\
\hline 0943 & 121.1302 & 22.7811 & $-3.1 \pm 4.3$ & CMS \\
\hline $205 \mathrm{R} 2$ & 121.1568 & 22.7818 & $-5.4 \pm 2.6$ & CMS+Leveling \\
\hline $38 \mathrm{R} 2$ & 121.1326 & 22.7932 & $-12.6 \pm 3.6$ & CMS+Leveling \\
\hline 8004 & 121.0781 & 22.7765 & $-5.5 \pm 3.3$ & Leveling \\
\hline 8005 & 121.0916 & 22.7752 & $-16.1 \pm 4.9$ & Leveling \\
\hline 8006 & 121.0993 & 22.7793 & $-19.3 \pm 4.9$ & Leveling \\
\hline 8011 & 121.1663 & 22.7791 & $-6.1 \pm 1.5$ & Leveling \\
\hline 8013 & 121.1860 & 22.7967 & $-2.6 \pm 0.7$ & Leveling \\
\hline 8014 & 121.1875 & 22.8096 & $-1.2 \pm 0.8$ & Leveling \\
\hline 8015 & 121.1814 & 22.8230 & $1.0 \pm 0.0$ & Leveling \\
\hline 8049 & 121.1290 & 22.9476 & $2.6 \pm 1.7$ & CMS \\
\hline 8050 & 121.1361 & 22.9269 & $-6.1 \pm 1.0$ & CMS+Leveling \\
\hline 8051 & 121.1282 & 22.9125 & $-3.5 \pm 0.5$ & Leveling \\
\hline 8052 & 121.1276 & 22.8951 & $5.3 \pm 3.7$ & CMS+Leveling \\
\hline 8055 & 121.0911 & 22.8751 & $-8.7 \pm 0.4$ & Leveling \\
\hline 8057 & 121.0843 & 22.8512 & $-6.7 \pm 1.1$ & Leveling \\
\hline 8058 & 121.0858 & 22.8356 & $-2.4 \pm 4.6$ & CMS+Leveling \\
\hline 8059 & 121.0814 & 22.8176 & $-5.1 \pm 3.0$ & Leveling \\
\hline 9171 & 121.1290 & 22.9507 & $-17.5 \pm 3.9$ & CMS \\
\hline 9172 & 121.1371 & 22.9336 & $-1.8 \pm 4.4$ & CMS+Leveling \\
\hline 9174 & 121.1285 & 22.9018 & $-8.9 \pm 2.0$ & Leveling \\
\hline 9175 & 121.1145 & 22.8957 & $-1.5 \pm 2.5$ & Leveling \\
\hline 9176 & 121.0920 & 22.9015 & $-9.4 \pm 4.7$ & CMS+Leveling \\
\hline 9177 & 121.0870 & 22.8954 & $-9.9 \pm 1.0$ & Leveling \\
\hline 9178 & 121.0963 & 22.8823 & $-7.9 \pm 1.3$ & Leveling \\
\hline 9179 & 121.0866 & 22.8658 & $-7.3 \pm 2.9$ & CMS+Leveling \\
\hline 9180 & 121.0842 & 22.8551 & $-6.1 \pm 1.6$ & Leveling \\
\hline 9181 & 121.0858 & 22.8328 & $-7.6 \pm 0.0$ & Leveling \\
\hline 9182 & 121.0848 & 22.8083 & $-8.0 \pm 0.5$ & Leveling \\
\hline 9183 & 121.0950 & 22.7966 & $-8.4 \pm 2.6$ & Leveling \\
\hline 9184 & 121.1073 & 22.7877 & $-11.1 \pm 3.7$ & CMS+Leveling \\
\hline 9188 & 121.0852 & 22.7760 & $-13.9 \pm 5.2$ & Leveling \\
\hline 9189 & 121.0669 & 22.7726 & $3.3 \pm 9.0$ & Leveling \\
\hline 9190 & 121.0421 & 22.7649 & $1.1 \pm 17.8$ & CMS+Leveling \\
\hline A084 & 121.1848 & 22.8175 & $-6.9 \pm 1.6$ & Leveling \\
\hline A086 & 121.1851 & 22.7955 & $-3.7 \pm 0.0$ & Leveling \\
\hline A087 & 121.1750 & 22.7902 & $-3.8 \pm 1.0$ & Leveling \\
\hline A089 & 121.1561 & 22.7678 & $-6.5 \pm 4.9$ & CMS+Leveling \\
\hline A090 & 121.1387 & 22.7503 & $-7.3 \pm 0.0$ & Leveling \\
\hline A091 & 121.1137 & 22.7383 & $-9.9 \pm 5.7$ & CMS+Leveling \\
\hline A092 & 121.0996 & 22.7318 & $-11.6 \pm 0.0$ & Leveling \\
\hline A093 & 121.0766 & 22.7221 & $-11 \pm 0.0$ & Leveling \\
\hline A094 & 121.0603 & 22.7123 & $-8.1 \pm 0.0$ & Leveling \\
\hline A095 & 121.0469 & 22.7065 & $-3.3 \pm 0.0$ & Leveling \\
\hline
\end{tabular}

Table 1. (Continued)

\begin{tabular}{|c|c|c|c|c|}
\hline Station & Lon & Lat & $\begin{array}{c}\text { Velocity } \\
\left(\mathbf{m m ~ y r}^{-1}\right)\end{array}$ & Type \\
\hline DULI & 121.3225 & 23.0275 & $3.4 \pm 0.4$ & CORS \\
\hline E322 & 121.1146 & 22.7770 & $-17.2 \pm 6.8$ & CMS \\
\hline ERPN & 121.1580 & 22.9440 & $7.9 \pm 0.1$ & CORS \\
\hline G3154 & 121.1083 & 22.8213 & $-7.0 \pm 5.1$ & Leveling \\
\hline GE04 & 121.1275 & 22.7920 & $-11.6 \pm 3.2$ & Leveling \\
\hline $\mathrm{I} 130$ & 121.1507 & 22.7937 & $-13.4 \pm 2.7$ & CMS \\
\hline $\mathrm{I} 138$ & 121.1012 & 22.8665 & $6.8 \pm 1.1$ & CMS \\
\hline LONT & 121.1225 & 22.9081 & $-0.7 \pm 0.1$ & CORS \\
\hline N623 & 121.2840 & 23.0411 & $3.0 \pm 2.5$ & CMS \\
\hline PEIN & 121.1151 & 22.8029 & $-4.5 \pm 0.2$ & CORS \\
\hline S040 & 121.1419 & 23.0324 & $-10.5 \pm 0.5$ & CMS \\
\hline S043 & 120.9269 & 22.4735 & $-10.6 \pm 1.2$ & CMS \\
\hline S044 & 121.0144 & 22.6796 & $-7.9 \pm 0.7$ & CMS \\
\hline S045 & 121.0724 & 22.8821 & $-5.9 \pm 1.0$ & CMS \\
\hline S054 & 121.1894 & 22.7958 & $-2.7 \pm 0.6$ & CMS \\
\hline S056 & 121.1904 & 23.0387 & $2.9 \pm 0.8$ & CMS \\
\hline S057 & 121.3012 & 22.9748 & $7.1 \pm 1.6$ & CMS \\
\hline S063 & 121.4704 & 22.6664 & $-1.0 \pm 0.8$ & CMS \\
\hline S072 & 121.1545 & 22.9274 & $6.6 \pm 1.1$ & CMS \\
\hline S104 & 121.1813 & 22.8226 & $1.4 \pm 0.1$ & CORS \\
\hline S105 & 121.1048 & 22.9535 & $-3.1 \pm 0.1$ & CORS \\
\hline S126 & 121.1423 & 22.8919 & $19.5 \pm 1.4$ & CMS \\
\hline S127 & 121.1444 & 22.9435 & $-6.9 \pm 1.1$ & CMS+Leveling \\
\hline $\mathrm{S} 128$ & 121.1492 & 22.9420 & $-10.7 \pm 1.3$ & CMS+Leveling \\
\hline S193 & 121.1608 & 22.9429 & $19.7 \pm 3.2$ & CMS+Leveling \\
\hline S194 & 121.1560 & 22.9447 & $-3.6 \pm 2.6$ & CMS+Leveling \\
\hline S195 & 121.1278 & 22.9337 & $-1.2 \pm 1.4$ & CMS+Leveling \\
\hline S196 & 121.1245 & 22.9366 & $-2.2 \pm 2.3$ & CMS+Leveling \\
\hline S197 & 121.1201 & 22.9392 & $-1.3 \pm 2.2$ & CMS+Leveling \\
\hline S198 & 121.1187 & 22.9405 & $-1.1 \pm 1.6$ & CMS+Leveling \\
\hline S199 & 121.1277 & 22.9076 & $-1.6 \pm 3.9$ & CMS+Leveling \\
\hline S200 & 121.1171 & 22.9055 & $-0.7 \pm 2.7$ & CMS+Leveling \\
\hline S201 & 121.1087 & 22.9058 & $1.8 \pm 3.0$ & CMS+Leveling \\
\hline S202 & 121.1063 & 22.9059 & $1.1 \pm 0.3$ & Leveling \\
\hline S203 & 121.1031 & 22.9060 & $-5.6 \pm 2.4$ & CMS+Leveling \\
\hline S204 & 121.0933 & 22.9071 & $-10.6 \pm 0.7$ & Leveling \\
\hline S205 & 121.0847 & 22.9097 & $-8.5 \pm 3.5$ & CMS+Leveling \\
\hline S206 & 121.0839 & 22.9158 & $-5.9 \pm 1.5$ & CMS+Leveling \\
\hline S207 & 121.1165 & 22.9416 & $-3.4 \pm 2.0$ & CMS+Leveling \\
\hline S209 & 121.0730 & 22.9039 & $-3.4 \pm 1.6$ & CMS \\
\hline S210 & 121.1345 & 22.9531 & $-22.3 \pm$ & CMS \\
\hline S211 & 121.0868 & 22.8824 & $-3.7 \pm 2.2$ & CMS \\
\hline S212 & 121.1328 & 22.8709 & $21 \pm 2.7$ & CMS \\
\hline S213 & 121.1147 & 22.9191 & $4.9 \pm 2.1$ & CMS \\
\hline S214 & 121.2324 & 22.9648 & $4.9 \pm 1.4$ & CMS \\
\hline S215 & 121.1025 & 22.8758 & $4.3 \pm 2.5$ & CMS \\
\hline S216 & 121.1140 & 22.8733 & $-8.9 \pm 2.2$ & CMS \\
\hline S217 & 121.1353 & 22.8698 & $27.5 \pm 2.4$ & CMS \\
\hline
\end{tabular}


Table 1. (Continued)

\begin{tabular}{|c|c|c|c|c|}
\hline Station & Lon & Lat & $\begin{array}{c}\text { Velocity } \\
\left(\mathbf{m m} \mathbf{y r}^{-1}\right)\end{array}$ & Type \\
\hline S218 & 121.1488 & 22.8676 & $17.0 \pm 1.1$ & CMS \\
\hline S219 & 121.1097 & 22.8792 & $-3.8 \pm 2.4$ & CMS \\
\hline S221 & 121.2608 & 22.9301 & $-4.1 \pm 1.1$ & CMS \\
\hline $\mathrm{S} 230$ & 121.1712 & 23.0359 & $-1.5 \pm 1.6$ & CMS \\
\hline S231 & 121.1649 & 23.0409 & $-13.8 \pm 1.1$ & CMS \\
\hline S232 & 121.2090 & 22.9448 & $16.9 \pm 3.0$ & CMS \\
\hline S233 & 121.1518 & 23.0460 & $-11.3 \pm 1.9$ & CMS \\
\hline S234 & 121.1321 & 22.9088 & $-5.3 \pm 0.5$ & Leveling \\
\hline S236 & 121.1434 & 22.9039 & $11.5 \pm 2.0$ & Leveling \\
\hline S237 & 121.1414 & 22.8995 & $19.9 \pm 13.4$ & CMS+Leveling \\
\hline S238 & 121.1063 & 22.9059 & $-5.0 \pm 3.2$ & CMS \\
\hline S239 & 121.0933 & 22.9071 & $6.2 \pm 9.3$ & CMS \\
\hline S240 & 121.0539 & 22.9009 & $-3.8 \pm 1.7$ & CMS \\
\hline S243 & 121.0402 & 22.8943 & $-11.4 \pm 2.3$ & CMS \\
\hline S245 & 121.1292 & 22.9808 & $-3.6 \pm 2.9$ & CMS+Leveling \\
\hline S246 & 121.1567 & 22.9758 & $-9.5 \pm 3.0$ & CMS+Leveling \\
\hline S247 & 121.1688 & 22.9750 & $14.9 \pm 4.4$ & Leveling \\
\hline S248 & 121.1786 & 22.9773 & $13.4 \pm 2.5$ & CMS+Leveling \\
\hline S260 & 121.0865 & 22.8026 & $-5.5 \pm 8.6$ & CMS+Leveling \\
\hline S261 & 121.0896 & 22.8105 & $-5.1 \pm 1.5$ & Leveling \\
\hline S262 & 121.0888 & 22.8171 & $-6.5 \pm 4.3$ & CMS+Leveling \\
\hline S263 & 121.0922 & 22.8258 & $-3.1 \pm 3.1$ & CMS+Leveling \\
\hline S264 & 121.1471 & 22.7621 & $-13.6 \pm 4.4$ & CMS \\
\hline S265 & 121.1170 & 22.8066 & $-10.5 \pm 8.9$ & CMS+Leveling \\
\hline S266 & 121.1200 & 22.7860 & $-20.0 \pm 5.2$ & CMS+Leveling \\
\hline S267 & 121.1294 & 22.7918 & $-10.1 \pm 6.4$ & CMS+Leveling \\
\hline S270 & 121.1026 & 22.7739 & $-18.5 \pm 3.8$ & CMS \\
\hline S271 & 121.1101 & 22.7565 & $-13.4 \pm 3.3$ & CMS \\
\hline S272 & 121.0689 & 22.7929 & $-6.3 \pm 6.2$ & CMS+Leveling \\
\hline S273 & 121.0547 & 22.7671 & $-7.2 \pm 11.5$ & CMS+Leveling \\
\hline S274 & 121.1005 & 22.7804 & $-27.8 \pm 9.1$ & CMS+Leveling \\
\hline S276 & 121.0784 & 22.7838 & $-13.0 \pm 2.4$ & Leveling \\
\hline S280 & 121.0453 & 22.7925 & $-7.9 \pm 6.8$ & CMS \\
\hline S281 & 121.1111 & 22.8165 & $-8.4 \pm 2.6$ & Leveling \\
\hline S282 & 121.1145 & 22.8120 & $-10.6 \pm 1.5$ & Leveling \\
\hline SINL & 121.2465 & 22.9101 & $9.1 \pm 0.8$ & CORS \\
\hline TMAM & 120.9994 & 22.6179 & $-1.5 \pm 0.1$ & CORS \\
\hline TP44 & 121.1016 & 22.8214 & $-9.6 \pm 4.8$ & Leveling \\
\hline TTSH & 121.1476 & 22.7471 & $-6.7 \pm 0.4$ & CORS \\
\hline TTUN & 121.0726 & 22.7664 & $-6.7 \pm 0.1$ & CORS \\
\hline V108 & 121.1491 & 22.9757 & $-3.7 \pm 5.2$ & CMS+Leveling \\
\hline V109 & 121.1663 & 22.9747 & $1.1 \pm 4.5$ & CMS+Leveling \\
\hline V110 & 121.1750 & 22.9742 & $20.9 \pm 1.4$ & Leveling \\
\hline V171 & 121.1004 & 22.8455 & $3.2 \pm 2.6$ & CMS \\
\hline W048 & 121.1457 & 22.9031 & $4.3 \pm 15.4$ & CMS+Leveling \\
\hline X005 & 121.0386 & 22.6926 & $-3.6 \pm 0.0$ & Leveling \\
\hline
\end{tabular}

in the Luyeh area (e.g., station LONT, Fig. 6) and of about $13 \mathrm{~mm}$ in the Taitung alluvial plain (e.g., station TTUN, Fig. 6). In contrast, the 2004 Lutao earthquake showed relatively less upward movement in the north but more significant change in the south, for instance, $10 \mathrm{~mm}$ at LONT and $27 \mathrm{~mm}$ at TTUN. Although the effects of the nearby earthquakes were not homogenous within the Longitudinal Valley, the general upward movement can clearly be observed. It is interesting and worth noting that this upward motion is demonstrable despite the general interseismic subsidence trend of the Longitudinal Valley. As a manifest, the nearby earthquakes decrease the total subsidence of the valley in a long-term time span. It is worth noting that the 2006 Peinan

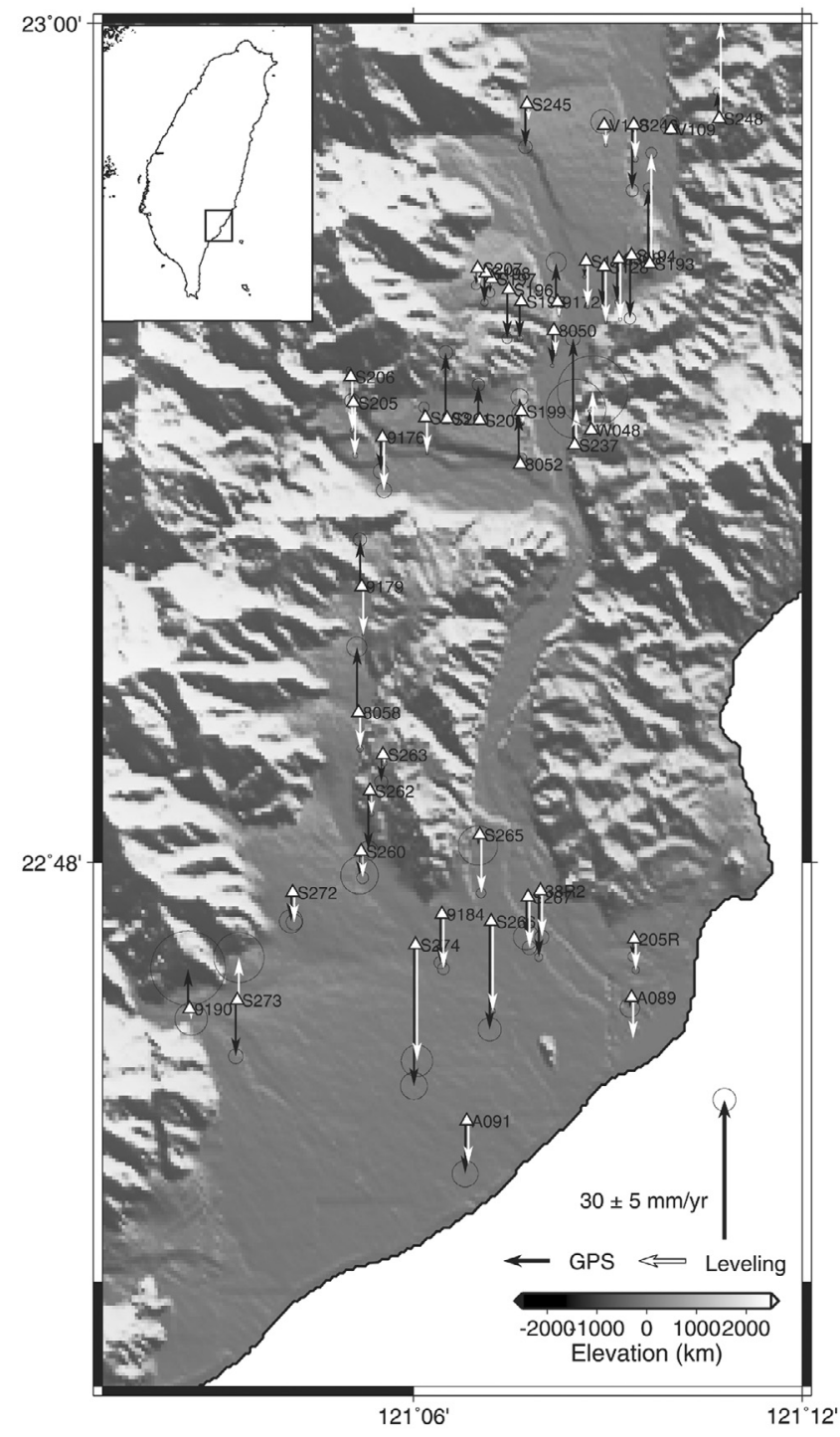

Fig. 13. The difference of vertical velocities yielded between GPS heighting and precise leveling on 44 common stations in the study area. See detailed statistical results in Table 1. The largest discrepancies can be observed on the northern part of the study, which is interpreted to be due to longer distances from the reference station (S104/8015). See detailed explanations in the main text. 
Table 2. Detailed results of yielded interseismic vertical velocities at each GPS station and leveling benchmark and difference between GPS and leveling analyses.

\begin{tabular}{|c|c|c|c|}
\hline Station & $\begin{array}{l}\text { GPS velocity } \\
\left(\mathrm{mm} \mathrm{yr}^{-1}\right)\end{array}$ & $\begin{array}{l}\text { Leveling Velocity } \\
\left(\mathrm{mm} \mathrm{yr}^{-1}\right)\end{array}$ & $\begin{array}{c}\text { GPS-Leveling } \\
\left(\mathbf{m m ~} \mathbf{y r}^{-1}\right)\end{array}$ \\
\hline 0308 & $-9.3 \pm 1.0$ & $-13.1 \pm 0.7$ & $3.8 \pm 1.2$ \\
\hline $205 R$ & $-3.8 \pm 2.1$ & $-6.7 \pm 1.6$ & $2.9 \pm 2.6$ \\
\hline $38 \mathrm{R} 2$ & $-14.2 \pm 1.8$ & $-9.9 \pm 3.1$ & $-4.3 \pm 3.6$ \\
\hline 8050 & $-7.5 \pm 0.8$ & $-5.1 \pm 0.6$ & $-2.4 \pm 1.0$ \\
\hline 8052 & $11.0 \pm 3.0$ & $1.3 \pm 2.1$ & $9.7 \pm 3.7$ \\
\hline 8058 & $14.1 \pm 4.4$ & $-7.7 \pm 1.4$ & $21.8 \pm 4.6$ \\
\hline 9172 & $8.5 \pm 4.4$ & $-3.0 \pm 0.5$ & $11.5 \pm 4.4$ \\
\hline 9176 & $-7.3 \pm 3.3$ & $-11.4 \pm 3.3$ & $4.1 \pm 4.7$ \\
\hline 9179 & $10.1 \pm 2.9$ & $-10.3 \pm 0.5$ & $20.4 \pm 2.9$ \\
\hline 9184 & $-10.4 \pm 2.7$ & $-11.7 \pm 2.6$ & $1.3 \pm 3.7$ \\
\hline 9190 & $8.7 \pm 16.3$ & $-2.2 \pm 7.1$ & $10.9 \pm 17.8$ \\
\hline A089 & $-2.2 \pm 4.3$ & $-8.9 \pm 0.0$ & $6.7 \pm 4.3$ \\
\hline A091 & $-11.3 \pm 5.7$ & $-9.3 \pm 0.0$ & $-2.0 \pm 5.7$ \\
\hline S127 & $-3.4 \pm 0.8$ & $-9.9 \pm 0.7$ & $6.5 \pm 1.1$ \\
\hline S128 & $-8.6 \pm 1.1$ & $-11.9 \pm 0.6$ & $3.3 \pm 1.3$ \\
\hline S193 & $16.2 \pm 2.1$ & $23.7 \pm 2.4$ & $-7.5 \pm 3.2$ \\
\hline S194 & $-13.5 \pm 2.5$ & $-1.2 \pm 0.6$ & $-12.3 \pm 2.6$ \\
\hline S195 & $-7.9 \pm 1.3$ & $0.8 \pm 0.4$ & $-8.7 \pm 1.4$ \\
\hline S196 & $-10.5 \pm 2.2$ & $0.1 \pm 0.6$ & $-10.6 \pm 2.3$ \\
\hline S197 & $-3.0 \pm 2.1$ & $-0.6 \pm 0.8$ & $-2.4 \pm 2.2$ \\
\hline S198 & $-6.3 \pm 1.6$ & $0.2 \pm 0.4$ & $-6.5 \pm 1.6$ \\
\hline S199 & $3.0 \pm 3.8$ & $0.2 \pm 0.4$ & $2.8 \pm 3.8$ \\
\hline S200 & $7.6 \pm 2.7$ & $-0.7 \pm 0.0$ & $8.3 \pm 2.7$ \\
\hline S201 & $14.2 \pm 3.0$ & $-1.0 \pm 0.2$ & $15.2 \pm 3.0$ \\
\hline S203 & $2.3 \pm 2.3$ & $-7.6 \pm 0.6$ & $9.9 \pm 2.4$ \\
\hline S205 & $0.3 \pm 3.3$ & $-11.4 \pm 1.1$ & $11.7 \pm 3.5$ \\
\hline S206 & $1.5 \pm 1.2$ & $-11.5 \pm 0.9$ & $13.0 \pm 1.5$ \\
\hline S207 & $-3.6 \pm 2.0$ & $-3.4 \pm 0.1$ & $-0.2 \pm 2.0$ \\
\hline S237 & $22.9 \pm 3.2$ & $7.8 \pm 13.0$ & $15.1 \pm 13.4$ \\
\hline S245 & $-9.2 \pm 2.9$ & $-3.4 \pm 0.1$ & $-5.8 \pm 2.9$ \\
\hline S246 & $-14.0 \pm 2.7$ & $-7.3 \pm 1.3$ & $-6.7 \pm 3.0$ \\
\hline S248 & $5.8 \pm 1.8$ & $20.9 \pm 1.8$ & $-15.1 \pm 2.5$ \\
\hline S260 & $-5.1 \pm 8.2$ & $-5.6 \pm 2.6$ & $0.5 \pm 8.6$ \\
\hline S262 & $-12.8 \pm 4.2$ & $-4.9 \pm 1.1$ & $-7.9 \pm 4.3$ \\
\hline S263 & $-5.9 \pm 2.9$ & $-1.9 \pm 1.2$ & $-4.0 \pm 3.1$ \\
\hline S265 & $-2.3 \pm 8.6$ & $-12.5 \pm 2.1$ & $10.2 \pm 8.9$ \\
\hline S266 & $-23.2 \pm 5.1$ & $-19.3 \pm 1.2$ & $-3.9 \pm 5.2$ \\
\hline S267 & $-8.6 \pm 5.6$ & $-10.9 \pm 3.1$ & $2.3 \pm 6.4$ \\
\hline S272 & $-6.2 \pm 5.1$ & $-6.4 \pm 3.5$ & $0.2 \pm 6.2$ \\
\hline S273 & $-12.0 \pm 3.2$ & $9.2 \pm 11.0$ & $-21.2 \pm 11.5$ \\
\hline S274 & $-30.3 \pm 5.9$ & $-24.9 \pm 6.9$ & $-5.4 \pm 9.1$ \\
\hline V108 & $0.8 \pm 5.2$ & $-4.3 \pm 0.7$ & $5.1 \pm 5.2$ \\
\hline V109 & $1.0 \pm 4.2$ & $1.2 \pm 1.5$ & $-0.2 \pm 4.5$ \\
\hline W048 & $4.1 \pm 0.6$ & $8.4 \pm 15.4$ & $-4.3 \pm 15.4$ \\
\hline
\end{tabular}

earthquake produced co- and post-seismic subsidence in the valley, which is in an opposite sense of movement than the above two nearby earthquakes.

With regard to the Coastal Range area, we also observe upward motions induced by the two nearby earthquakes, which were even more significant than those in the Longitudinal Valley. For instance, the Chengkung earthquake produced more than $100 \mathrm{~mm}$ of combined co- and postseismic uplift in both western (station EPRN) and eastern (station S104) Coastal Range. The Lutao earthquake induced approximately 50 to $60 \mathrm{~mm}$ uplift for the two stations, respectively. It is not surprising because the two nearby earthquakes ruptured primarily within the Longitudinal Valley Fault system. First, the Coastal Range represents the hanging wall of this thrust system and second, it is close to the epicenter. With regard to the Peinan earthquake, it also produced upward motion in the Coastal Range, but less than the two nearby earthquakes referenced above. As a result, it is obvious that the perturbation of these two nearby earthquakes (as well as the earthquake rupture in the blind Central Range Fault) strengthened the general uplifting interseismic trend of the Coastal Range in the study area over the long term.

In sum, it is relatively difficult to estimate long-term vertical deformation around the southernmost Longitudinal Valley precisely. In order to do that, one would require summing up not only the interseismic secular and co-seismic deformation, but also perturbations of nearby moderate to large earthquakes, which could occur frequently. It is actually more complex than this. At least in the study area, there are two distinct sources for co-seismic events: (1) the seemingly blind, west-dipping thrust on the western side of the Longitudinal Valley and (2) the Longitudinal Valley fault system with two surface strands on both sides of the valley.

\section{CONCLUSION}

In an attempt to reconstruct the vertical velocity field of the surficial crustal deformation in the southernmost Longitudinal Valley, the suture between Philippine Sea and Eurasia plates in eastern Taiwan, we integrated 10-year leveling measurements and GPS monitoring. The detailed analyses and the yielded vertical deformation results can be enumerated as follows.

(1) By removing the leveling surveys during the periods with co- and post-seismic effects, we fit the data into linear trends and estimate the interseismic vertical deformation rates along 6 leveling routes, including $5 \mathrm{E}-\mathrm{W}$ routes across the Longitudinal Valley and $1 \mathrm{~N}-\mathrm{S}$ route along the western valley in the study area.

(2) By removing the perturbations of the four major large earthquakes, including the $1999 \mathrm{M}_{\mathrm{w}}$ 7.6 Chi-Chi earthquake, $2003 \mathrm{M}_{\mathrm{w}}$ 6.8 Chengkung earthquake, 2004 M 6.0 
Lutao earthquake and $2006 \mathrm{M}_{\mathrm{w}} 6.1$ Peinan earthquake, we estimate the interseismic vertical velocity for 88 campaigned GPS and 8 continuous GPS stations in the study area.

(3) By adopting a common reference for both leveling and GPS heigting, station S104 which is of 16-year observation time with a rather stable and a very slow rate $\left(1.4 \mathrm{~mm} \mathrm{yr}^{-1}\right)$ of vertical motion. We combined the leveling velocity and the GPS velocity to reconstruct a map of interseismic vertical velocity in the southernmost Longitudinal Valley area, with respect to the stable Chinese continental margin at the Penghu island (station S01R) in the Taiwan Strait.

(4) Based upon our results, the most dominant interseismic uplift is located in the hanging wall close to the Lichi fault (i.e., the eastern strand of the two branches system of the LVF) in the western margin of the Coastal

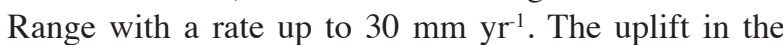
Coastal Range diminishes eastward away from the fault and southward as the Coastal Range transitions into the Taitung alluvial plain. The perturbations of the nearby moderate and large earthquakes also produced uplift in the Coastal Range.

(5) The eastern margin of the Central Range reveals interseismic subsidence at a rate of -5 to $-10 \mathrm{~mm} \mathrm{yr}^{-1}$ with respect to station S01R in the Chinese continental margin, which is contrary to the co-seismic upward motion due to nearby moderate to large earthquakes.

(6) In between the two ranges, the Longitudinal Valley shows a general trend of interseismic subsidence but with a rather large variation; and, some small uplift (less than $10 \mathrm{~mm} \mathrm{yr}^{-1}$ ) also occurred in the middle part of the tableland areas (the Pinanshan massif and Luyeh-Gaotai terrace high). A trend of significant subsidence at a rate of -10 to $-25 \mathrm{~mm} \mathrm{yr}^{-1}$ occurred in the flat areas with alluvial deposits. The perturbations of nearby earthquakes also revealed effects containing a variation with complex uplift and subsidence patterns.

(7) We interpret the interseismic vertical deformation in the southernmost Longitudinal Valley to be due primarily by creeping/thrusting on two strands of the Longitudinal Valley fault, the Luyeh fault and the Lichi fault. On one hand,significant uplift occurs on each hanging wall close to the faults; on the other hand, substantial subsidence occurs on each footwall of the faults. It appears that the eastern margin of the Central Range did not show interseismic uplift, which is contrary to its long-term highrange topography. As a result, the blind west-dipping reverse left-lateral fault under the eastern Central Range (e.g., the causative fault of the 2006 Peinan earthquake) was apparently strongly locked during the interseismic time.
Acknowledgements The authors would like to express their sincere thanks to their colleagues and assistants who have devoted their effort to the geodetic surveys for this study. The International GPS Service (IGS) has provided the precise ephemerides for data processing. We also thank two anonymous reviewers for their constructive comments and suggestions which indeed help improve the manuscript. This research was supported by the Taiwan Earthquake Research Center (TEC) funded through the National Science Council with the grant number NSC98-2119-M-001-031 and NSC100-2116-M-001-004. The paper is a contribution from the Institute of Earth Sciences, Academia Sinica, IESAS1653, and the TEC contribution number for this article is 00083 .

\section{REFERENCES}

Angelier, J., 1994: Fault slip analysis and paleostress reconstruction. In: Hancock, P. (Ed.), Continental Deformation, Pergamon, Oxford, 101-120.

Biq, C. C., 1965: The eastern Taiwan rift. Petrol. Geol. Taiwan, 4, 93-106.

Biq, C. C., 1972: Dual trench structure in the Taiwan-Luzon region. Proc. Geol Soc. China, 15, 65-75.

Chen, H. Y., S. B. Yu, L. C. Kuo, and C. C. Liu, 2006: Coseismic and postseismic surface displacements of the 10 December $2003\left(M_{w} 6.5\right)$ Chengkung, eastern Taiwan, earthquake. Earth Planets Space, 58, 5-21.

Chen, H. Y., Y. J. Hsu, J. C. Lee, S. B. Yu, L. C. Kuo, Y. L. Jiang, C. C. Liu, and C. S. Tsai, 2009: Coseismic displacements and slip distribution from GPS and leveling observations for the 2006 Peinan earthquake $\left(M_{w}\right.$ 6.1) in southeastern Taiwan. Earth Planets Space, 61, 299-318.

Chen, H. Y., H. Tung, and S. B. Yu, 2011: A new velocity field from a dense GPS array in south eastern Taiwan, GPS/GNSS conference in University of New South Wales, Sydney, NSW, Australia, 15-17 November, IGNSS Symposium peer review No. 1.

Crespi, J. M., Y. C. Chan, and M. S. Swaim, 1996: Synorogenic extension and exhumation of the Taiwan hinterland. Geology, 24, 247-250, doi: 10.1130/0091-7613 (1996)024<0247:SEAEOT>2.3.CO;2. [Link]

Dach, R., U. Hugentobler, P. Fridez, and M. Meindl, 2007: Bernese GPS Software Version 5.0, User manual, Astronomical Institute, University of Bern, $612 \mathrm{pp}$.

Ho, C. S., 1975: An Interpretation to the Geology of Taiwan: Explanatory Text of the Geologic Map of Taiwan, Ministry of Economic Affairs, Taipei, Taiwan, ROC, 153 pp.

Hsu, L. and R. Bürgmann, 2006: Surface creep along the Longitudinal Valley fault, Taiwan from InSAR measurements. Geophys. Res. Lett., 33, L06312, doi: 10.10 29/2005GL024624. [Link] 
Kuo, L. C., 2010: GPSLAB, available at http://gps.earth. sinica.edu.tw/.

Lee, C. and S. B. Yu, 1985: Precision of distance measurements for observing horizontal crustal deformation in Taiwan. Bull. Inst. Earth Sci., Academia Sinica, 5, 161-174.

Lee, J. C. and J. Angelier, 1993: Localisation des déformations actives et traitement des données géodésiques: l'example de la faille de la Vallée Longitudinale, Taïwan. Bull. Soc. Géol. France, 164, 533-540.

Lee, J. C., J. Angelier, H. T. Chu, S. B. Yu, and J. C. Hu, 1998: Plate-boundary strain partitioning along the sinistral collision suture of the Philippine and Eurasian plates: Analysis of geodetic data and geological observation in southeastern Taiwan. Tectonics, 17, 859-871, doi: 10.1029/98TC02205. [Link]

Lee, J. C., H. T. Chu, J. Angelier, J. C. Hu, H. Y. Chen, and S. B. Yu, 2006: Quantitative analysis of surface coseismic faulting and postseismic creep accompanying the 2003, $M_{w}=6.5$, Chengkung earthquake in eastern Taiwan. J. Geophys. Res., 111, B02405, doi: 10.1029/2005JB003612. [Link]

Liu, C. C. and S. B. Yu, 1990: Vertical crustal movements in eastern Taiwan and their tectonic implications. Tectonophysics, 183, 111-119, doi: 10.1016/0040-1951(90) 90191-A. [Link]

Lu, C. Y. and K. J.Hsu, 1992: Tectonic evolution of the Taiwan mountain belt. Petrol. Geol. Taiwan, 27, 21-46.

Nikolaidis, R., 2002: Observation of geodetic and seismic deformation with the Global Positioning System. Ph.D. Dissertation, University of California, San Diego, 249 pp.

O'hara, D., J. C. Lewis, and R. J. Rau, 2011: Slip partitioning offshore southeast Taiwan and southward propagation of the Longitudinal Valley Fault: Evidence from preferred nodal plane slip vectors, Session: T52C-05: Earthquake Geology and Seismotectonics in South and East Asia II, AGU fall meeting in San Francisco.

Peyret, M., S. Dominguez, R. Cattin, J. Champenois, M. Leroy, and A. Zajac, 2011: Present-day interseismic surface deformation along the Longitudinal Valley, eastern Taiwan, from a PS-InSAR analysis of the ERS satellite archives. J. Geophys. Res., 116, B03402, doi: 10.1029/2010JB007898. [Link]

Schomaker, M. C. and R. M. Berry, 1981: Geodetic leveling, NOS/NOAA, Rockville, Maryland.

Shyu, J. B. H., K. Sieh, R. Y. Chuang, Y., Wang, L. H. Chung, Y. G. Chen, and the Caltech Ge122 Group,
2002: River terrace deformation of the Luyeh River, eastern Taiwan, and the tectonic implications. 2002 Annual Meeting of Geological Society of China at Taipei, Abstract.

Shyu, J. B. H., K. Sieh, Y. G. Chen, and C. S. Liu, 2005: Neotectonic architecture of Taiwan and its implications for future large earthquakes. J. Geophys. Res., 110, B08402, doi: 10.1029/2004JB003251. [Link]

Shyu, J. B. H., K. Sieh, Y. G. Chen, R. Y. Chuang, Y. Wang, and L. H. Chung, 2008: Geomorphology of the southernmost Longitudinal Valley fault: Implications for evolution of the active suture of eastern Taiwan. Tectonics, 27, TC1019, doi: 10.1029/2006TC002060. [Link]

Wu, Y.M.,Y.G.Chen,C.H.Chang,L.H.Chung, T.L.Teng, F. T. Wu, and C. F. Wu, 2006: Seismogenic structure in a tectonic suture zone: With new constraints from $2006 \mathrm{M}_{\mathrm{w}} 6.1$ Taitung earthquake. Geophys. Res. Lett., 33, L22305, doi: 10.1029/2006GL027572. [Link]

Yen, J. Y., C. H.Lu, C. P. Chang, A. J. Hooper, Y. H. Chang, W. T. Liang, T. Y. Chang, M. S. Lin, and K. S. Chen, 2011: Investigating active deformation in the northern Longitudinal Valley and City of Hualien in eastern Taiwan using persistent scatterer and small-baseline SAR interferometry. Terr. Atmos. Ocean. Sci., 22, 291-304, doi: 10.3319/TAO.2010.10.25.01(TT). [Link]

Yu, S. B. and C. Lee, 1986: Geodetic measurement of horizontal crustal deformation in eastern Taiwan. Tectonophysics, 125, 73-85, doi: 10.1016/0040-1951(86) 90007-7. [Link]

Yu, S. B. and H. Y. Chen, 1994: Global Positioning System measurements of crustal deformation in the Taiwan arc-continent collision zone. Terr. Atmos. Ocean. Sci., 5, 477-498.

Yu, S. B. and L. C. Kuo, 2001: Present-day crustal motion along the Longitudinal Valley Fault, eastern Taiwan. Tectonophysics, 333, 199-217, doi: 10.1016/S0040-19 51(00)00275-4. [Link]

Yu, S. B., D. D. Jackson, G. K. Yu, and C. C. Liu, 1990: Dislocation model for crustal deformation in the Longitudinal Valley area, eastern Taiwan. Tectonophysics, 183, 97-109, doi: 10.1016/0040-1951(90)90190-J. [Link]

Yu, S. B., G. K. Yu, L. C. Kuo, and C. Lee, 1992: Crustal deformation in the southern Longitudinal Valley area, eastern Taiwan. J. Geol. Soc. China, 35, 219-230.

Yu, S. B., H. Y. Chen, and L. C. Kuo, 1997: Velocity field of GPS stations in the Taiwan area. Tectonophysics, 274, 41-59, doi: 10.1016/S0040-1951(96)00297-1. [Link] 